\title{
MODELING A CONTROL SYSTEM FOR ORGANIZATIONAL PROCESSES
}

\section{MARKUS SCHWANINGER}

Institute of Management, University of St. Gallen, St. Gallen, Switzerland

\section{STEPHEN G. POWELL CHRIS TRIMBLE}

\author{
Amos Tuck School of Business Administration, \\ Dartmouth College, Hanover, New Hampshire, USA
}

\begin{abstract}
It is widely accepted that any well designed organizational process includes a control mechanism through which management decides which aspects of the process performance are to be measured and how these measurements are to be used to change the level of resources utilized in the process. Little is known, however, about the best ways to design such a control mechanism for typical service sector processes. The focus of this research is to study how a variety of control mechanisms performs in managing a business process. The goal is to identify control mechanisms that are effective in different types of environments. This requires modeling both levels, the business process (object level), and the control system (meta level). The fundamental question we ask here is why control systems so often founder. We address the logical aspect of modeling only, not the socio-logical aspects of model use and of implementation. The scenarios for which we try to establish optimal control systems are ones of stationary, dynamic, and turbulent demand patterns. For
\end{abstract}

The authors thank Prof. Stuart Umpleby for valuable comments. They are also grateful to Mr. Urs Strukov-Baer, Research Associate at the Institute of Management at the University of St. Gallen, for his cooperation in elaborating a simulation model which preceded the one used for the purpose of this paper.

Address correspondence to Dr. Markus Schwaninger, Institute of Management, University of St. Gallen, Dufourstrasse 48, St. Gallen, CH-9008, Switzerland.

E-mail: Markus.Schwaninger@unisg.ch 
this purpose we have designed a generic system dynamics model of a business process. The extensive simulation experiments realized with this model corroborate some of the generally acknowledged, basic principles of control, while refuting some of the usually accepted common-sense knowledge about management and organization. The pertinent reflections also lead to some substantive conclusions concerning the design of control systems.

\section{INTRODUCTION}

\section{Why Do Control Systems Founder?}

In the 1990s, the redesign of organizational processes was an object of intensive and frequent discussion among consultants and their clients as well as among academics (e.g., Davenport 1993; Dutta and Manzoni 1999; Fairchild 1998; Gouillart and Kelly 1995; Hammer and Champy 1993; Österle 1995; Sinatra and Bhambri 1997). Much has been said about the redesign, reengineering, transformation, etc., of processes and ways to support them better by means of information technology. Also, the control of organizational processes has been discussed (e.g., Bauer et al. 1993; Espejo et al. 1996; Harvard Business Review, 1998; Hopp and Spearman 1996; Kaplan and Norton 1996; Macciariello and Kirby 1994; Schwaninger 1994). However, the respective treatises, while identifying what needs to be measured, stop short of specifying how to respond to deviations in the metrics and how to conceive specific mechanisms for an effective response. To our knowledge, mathematical control theory, studied mainly by mathematicians and engineers, has only received little attention in management theory and practice. ${ }^{1}$ We shall try to incorporate some useful notions of control theory into this article.

The question asked at the outset - why control systems founder - is fundamental and is difficult to answer on empirical grounds. First, it is fundamental because theory tells us that the result of a process can not be better than its control system, and in particular the model incorporated by that control system. ${ }^{2}$ More specifically, the result of a process can not be better than the model on which it is based, except by accident. Second, the question posed is difficult to answer on empirical grounds. If the managers of business processes that have failed are asked, "why did your

${ }^{1}$ A remarkable exception is found in La Roche (1994) and La Roche and Simon (1998).

${ }^{2}$ The laws referred to are Ashby's Law of Requisite Variety: "Only variety can absorb variety" (Ashby 1956), and the Conant-Ashby theorem: "Every good regulator of a system must be a [sufficiently rich] model of that system" (Conant and Ashby 1981). 
control system founder?,' they rarely can provide insightful answers. This is due not to the lack of intelligence of managers but to the difficulty of inferring the true drivers of performance in complex systems. On one hand, we could answer the questions posed at the outset on theoretical grounds: If a control system founders, the reason is that it is based on an insufficient model. Here we pursue a different strategy: to investigate, through models, how to design an effective control mechanism for organizational processes.

\section{Goal and Structure of the Paper}

Our goal is to find general rules for the design of control mechanisms. Such a large goal can only be achieved in a long-term effort. Therefore, what we can present in this paper must rather be considered an intermediate picture of work in progress, than a definite and comprehensive result.

The method used is a type of anticipative empiricism. We start out with the outline of a basic model of a business process and a pertinent control system. Then we present the results of a large number of simulation experiments and some general implications for the design of control mechanisms for organizational processes. We then expand on these results by examining several hypotheses to gain further insights into the (self-) control of complex systems of the organizational process type. Finally, conclusions for the design of control mechanisms are drawn.

\section{A MODEL FOR THE CONTROL OF ORGANIZATIONAL PROCESSES}

In this section, we build a mathematical model that has the essential ingredients of a generic business process. The following characteristics are essential to our model:

- Work arrives at an unpredictable rate.

- Work builds up in a queue whenever the work on hand exceeds the available labor force.

- The labor force must be chosen by management to best deal with the work on hand and the work likely to arrive.

- Management can measure three aspects of the performance of the process: the cycle time for completed work, the backlog of work on hand, and the arrival rate of new work.

- Management's direct goal is to maximize profit, but it must also keep the cycle time below a certain level or face dissatisfied customers. 
- Management's observation of the state of the system are subject to delays, and there are delays between a decision to change the labor force and the implementation of the change.

This model is capable of producing a level of complexity that is realistic with respect to actual business processes. It provides a useful laboratory within which to study different approaches to process control. By studying how simple control mechanisms work in this laboratory setting, we hope to derive useful insights for the control of real-world business processes.

\section{Overview of the Model}

The model reflects a business process of the type typically encountered in service sector businesses, e.g., insurance claims processing, credit card withdrawal approval, or college admissions applications processing. These processes have a small number of defining characteristics. First, they are labor intensive. Although information technology can and has been used to speed the flow of work, it has not proven capable of replacing human knowledge workers who are required to make expert judgments about individual cases. Second, demand for service, or the arrival of customers, is generally unpredictable and nonpostponable. For example, insurance applications arrive by mail whenever a customer sends one in, and although the process does not have to begin work on each application immediately, the customer generally determines his or her waiting time from the time of submission, not the time work begins. In contrast to the typical manufacturing process, in these processes the work required cannot be scheduled to match the available process resources. Instead, the resources must be provided to match the work. Third, there are no binding limits to the amount of work that can build up within the system. For example, even when insurance claims are filed on paper forms (rather than electronically) they do not consume enough space to encounter any practical storage limits. So again in contrast to the situation in a typical factory, controlling work in progress and cycle time by the arrival of work is not a feasible option for management. Finally, the time required to process a given customer may vary substantially due to differences among customers, workers, or other factors in the process.

Our model seeks to reproduce each of these characteristics of business processes. Work arrives unpredictably, perhaps randomly 
(according to a known probability distribution). That is to say, management can observe the pattern of work arriving but cannot entirely anticipate future arrivals (in the sense of making a precise prediction). Each unit of work (or job) is pushed through the process, that is, work begins at an activity as soon as a worker is available. Newly arriving work waits in a queue whenever the available labor force is fully occupied. There is unlimited storage capacity for work in process. Finally, the processing times for each job are governed by a known probability distribution.

We assume that management's operative goal for this process is to make as much profit as possible. That requires processing as many customers as possible in a given time period (each of which brings in a fixed amount of revenue upon completion) but with the minimum labor force possible - the major cost of the process is the cost of labor. In addition to maximizing profits, management wants to ensure that the cycle time of the process does not exceed a level that is acceptable to customers. We operationalize this second goal by measuring the percentage of customers for which the actual cycle time exceeds a cycle time limit. The cycle time limit is established by the competitive environment and is, therefore, not a decision variable.

The task faced by management is to constantly adjust the labor force to produce as much profit as possible while simultaneously ensuring that cycle times do not exceed the cycle time limit. In order to achieve these goals management measures three aspects of the state of the process: cycle time, backlog, and demand. Each of these measures is taken over an averaging interval, itself a decision variable. If the averaging interval is short, management gets a quick signal that the system is deviating from its previous state; however, in some environments this signal may actually contain mostly noise. In this case a longer averaging interval would give management a more accurate picture of the true state of the system. We also assume that the effects of management action, that is, changes in the labor force, take effect only with a lag.

The actual rules management uses to link observations of the process state to changes in resources involve three types of control: proportional, differential, and integral (Geering 1990). Assume for the moment that management has chosen to base its control policy only on its measurement of cycle time. (Similar control rules are used for the backlog and demand controllers.) Proportional control is identical to the first-order feedback rule commonly used in systems dynamics models. If, for 
example, the measured cycle time is 18 days and the target is 15 days, the labor force will be increased in proportion to the gap of 3 days between actual and target. Differential control uses first-order feedback as well, but this element of control is proportional to the first difference (between two points in time) in the gap between measured and target cycle times. Thus, if the gap is positive and widening, the use of differential control in addition to proportional control will lead to a stronger control response. Finally, integral control uses first-order feedback on the cumulative gap between measured and actual cycle times. This form of control can be helpful in cases in which the cumulative gap has an impact on performance, and can not be closed by proportional or differential control.

At the operational level, then, the task facing management is to choose which of the three measurements of process state (cycle time, backlog, or demand) to use in its control policy, and then to choose the control parameters (or gains) for the proportional, differential, and integral control inputs.

\section{Detailed Description of the Model}

We have implemented this model by means of ithink (High Performance Systems, Inc., Hanover, New Hampshire, USA), a software package designed to support simulation of dynamic systems. The model diagram and the equations in the ithink version are given in Appendix A. The model consists of the following sectors.

Demand Sector. The demand generator includes a set of parameters by which different environmental scenarios can be simulated. Five distinct types of demand environment are possible: step change, steady increase, spike, random, and seasonal. In the step change environment, demand increases once by a set amount. In the steady increase environment demand increases at a constant rate. The spike environment includes a single discrete spike in demand. In the random demand environment, average demand is constant but demand varies each period according to a normal distribution. Finally, in the seasonal environment demand cycles with a fixed amplitude and period.

Production Sector. Orders arrive according to the specified demand environment. If all workers are busy, arriving orders accumulate in a 
backlog. The available labor force, which varies according to changes in the adjustment sector, multiplied by labor force productivity, which may be subject to random fluctuations, determines the rate at which orders can be withdrawn from the backlog. Once withdrawn, there is a minimum time delay associated with fulfilling an order. This time delay plus any time spent waiting in the backlog is equal to the cycle time for that order.

Measurement Sector. Three aspects of the process state are measured: cycle time, backlog, and demand. Each is averaged over an averaging interval specified by management. Measured cycle time is simply the average cycle time over all work completed during the averaging interval. Similarly, measured demand is the average over the averaging interval of arriving work. Backlog is measured in days of work by dividing the average number of units of work in the backlog by the average amount of labor on hand.

Adjustment Sector. Labor force is the resource management uses to achieve its goals of high profit and low cycle times. It accomplishes this by choosing first which of the measurements (cycle time, backlog, or demand) to base its control policy on. Then it chooses parameter values for the proportional, differential, and integral gains for these measurements. For example, management could choose to control using only measured backlog, and to set the proportional gains to 0.01 while setting the other two gains to 0.0 .

Results Sector. The results sector accounts for profits and actual cycle times. Profit includes revenues for each unit of work completed less the costs of labor and the costs of staffing. The staffing charge is a one-time charge associated with searching for and training new hires.

The first two sectors of the model represent the process itself (operational domain), and the last three represent the control system (regulatory domain).

\section{Modeling and the Metamodeling Aspects}

From a modeling point of view, the design of this model involved the standard questions such as choice of the system-in-focus, definition of 
boundaries, goal and problem definition, choice of variables, their interrelationships and functions, validity, etc. This task was straightforward in the case of the system at hand.

Yet we believe we have found a highly general representation, applicable to a variety of real-life situations. We are conscious of not having depicted all relevant aspects of a business process. However, we have represented the tangible operational variables and their interrelationships in a model which fleshes out the dynamic functioning of a business process. This is already an aspect of a logically higher order ("metamodeling"; Van Gigch 1991).

In a certain sense, the emphasis of this article is on aspects of metamodeling. From a metamodeling point of view we have, in the first place, departed from a fundamental distinction between two types of control system:

1. Pragmatic control systems: These are control systems which essentially rely on trial and error, usually based on managerial intuition and personal experience.

2. Theory-based control systems: These are control systems which systematically draw on explicit knowledge about invariances and principles of control, in particular regularities in the relationships between control variables and outcomes.

Our observation in the world of organizations has been that, except for highly technical domains (e.g., the calibration of factory equipment), most of managerial control is realized on merely pragmatic grounds.

Therefore, in the second place, we decided to make a contribution to the development of theory-based control systems by examining some of the control principles which different sciences such as general systems theory, control theory, management science, and operations management, or even the oral tradition, have promulgated. We wished to corroborate or refute them on the grounds of extensive simulation experiments.

\section{BASIC TESTS}

Our method to reach the demanding goals of this article required extensive simulation runs as a basis for the exploration of our theoretical questions. 


\section{Control Systems Design-A Multidimensional Issue}

The setup for these experiments confronted us with a multidimensional issue. We concentrated on the following dimensions:

1. types of demand environments faced by the system-in-focus,

2. control variables,

3. types of controllers, and

4. goals and results (outcomes).

Other possible dimensions (e.g., technology, organizational embedment) were considered, but regarded as beyond the scope of this study.

\section{Simulation Experiments-Setup}

For the setup of our simulation experiments, we localized a number of manifestations in each one of the dimensions enumerated (Table 1). The abbreviations used in the following sections are summarized in a quick reference at the very end of the article (Appendix B).

In the first dimension - types of demand environments - we tested five distinct types of demand environments. In each case, the system starts in steady state, and on the 50th day, is "shocked" by a change in demand.

1. Step change: A sudden jump in demand, remaining constant thereafter (default jump $=50 \%$ ).

2. Random: A random, normally distributed time series of arriving orders (default standard deviation $=20 \%$ ).

3. Spike: A sudden spike in demand (default $=$ three times normal demand for one day).

4. Steady growth (or ramp): A linear increase of arriving orders $($ default $=5$ units per period).

Table 1. Setup of our study

\begin{tabular}{lllc}
\hline Demand environments & Feedback variables & Controllers & Outcomes \\
\hline Step increase & Cycle time & Proportional & Profit \\
Steady increase & Backlog & Differential & Excess cycle time \\
Spike increase & Demand & Integral & - \\
Random & - & - & - \\
Seasonal & - & - & - \\
\hline
\end{tabular}


5. Seasonal: A sinusoidal time series of orders (default periodicity $=180$, default variability $=50$ ).

In the second dimension - control variables - we concentrated on adjustments of labor force as a function of

- a cycle time (CT) error signal (defined as measured cycle time minus target cycle time),

- a backlog (BL) error signal (defined as measured backlog minus a backlog target), and

- a demand (DD) error signal (defined as measured demand minus processing capacity).

In the third dimension - types of controllers - the model contains four options, namely control via

- proportional gain (abbreviated in the following as "P"),

- differential gain (abbreviated in the following as "D"),

- integral gain (abbreviated in the following as "I"), and

- second-order differential gain (abbreviated in the following as "D2").

For technical details please consult the documentation of the model, equations in particular, in the appendices.

Consequently, a relatively large number of simulation experiments was run, along the multidimensional structure outlined. This way, the behavior of the model could be observed from all possible angles defined by the framework. We shall only reproduce in limited detail the enormous body of quantitative data obtained and to a large extent in qualitative form.

\section{Results}

The results of our basic runs are summarized in Table 2. The main aspect of this table is a comparison of outcomes achieved without controls as well as maximized optima achieved with controls, either on the CT, the $\mathrm{BL}$, or the DD signals. All simulations were run over a range of 5000 days. This long run length was chosen as one aspect of model validation (Barlas 1996; Forrester and Senge 1980). Details on the values of further parameters are included in Table 2. 
Table 2. Comparison of controls in different environments

\begin{tabular}{|c|c|c|c|c|c|c|c|}
\hline \multirow{5}{*}{$\begin{array}{l} \\
\text { Outcomes } \\
\text { achieved } \\
\text { without } \\
\text { controls }\end{array}$} & & Constant & Step & \multirow{2}{*}{$\frac{\text { Random }}{24^{\prime} 498}$} & Spike & Steady Increase & \multirow{2}{*}{$\frac{\text { Seasonal }}{25^{\prime} 000}$} \\
\hline & Profit & 25000 & $25^{\prime} 000$ & & 25000 & $25^{\prime} 000$ & \\
\hline & & & & & & & \\
\hline & $\%>$ CT & 0.0 & 98.4 & 38.4 & 0.0 & 97.9 & 71.1 \\
\hline & Avg. CT & 15.0 & 829.1 & 18.8 & 17.0 & 1891.8 & 29.1 \\
\hline & Max. CT & 15.0 & 1660.0 & 35.0 & 17.0 & 4052.0 & 44.0 \\
\hline & St.dev. CT & 0.0 & 479.6 & 5.8 & 0.2 & 1209.7 & 10.2 \\
\hline \multirow{6}{*}{$\begin{array}{l}\text { Best } \\
\text { outcomes } \\
\text { on profit } \\
\text { and } \%>\text { CT } \\
\text { achieved: }\end{array}$} & CT Control & Profit & 37252 & $24 ' 336$ & 25009 & 625161 & 22335 \\
\hline & & $\%>$ CT & 4.6 & 3.1 & 0.0 & 3.8 & 19.7 \\
\hline & BL Control & Profit & 37258 & $24 ' 374$ & 25009 & $625^{\prime} 928$ & 22347 \\
\hline & & $\%>$ CT & 0.1 & 0.0 & 0.0 & 0.0 & 19.2 \\
\hline & DD Control & Profit & 37215 & $24 ' 429$ & 25009 & 625238 & $23^{\prime} 763$ \\
\hline & & $\%>C T$ & 0.0 & 1.2 & 0.0 & 0.0 & 0.0 \\
\hline \multirow{9}{*}{$\begin{array}{l}\text { Overall } \\
\text { Perfor- } \\
\text { mance } \\
\text { optima } \\
\text { achieved: }\end{array}$} & CT Control & Performance & 0.98 & 0.94 & 1.00 & 1.00 & 0.72 \\
\hline & & Profit & $36^{\prime} 882$ & $23^{\prime} 791$ & $25^{\prime} 009$ & $625 ' 161$ & $20^{\prime} 440$ \\
\hline & & $\%>$ CT & 4.6 & 4.0 & 0.0 & 3.8 & 25.6 \\
\hline & BL Control & Performance & 1.00 & 0.91 & 1.00 & 1.00 & 0.74 \\
\hline & & Profit & 37238 & $23^{\prime} 840$ & 25009 & $625 ' 928$ & 17324 \\
\hline & & $\%>\mathrm{CT}$ & 0.1 & 1.4 & 0.0 & 0.0 & 19.2 \\
\hline & DD Control & Performance & 1.00 & 0.98 & 1.00 & 1.00 & 1.00 \\
\hline & & Profit & 37207 & 18240 & 25009 & 625238 & $22 ' 251$ \\
\hline & & $\%>C T$ & 0.0 & 1.2 & 0.0 & 0.0 & 0.0 \\
\hline
\end{tabular}

Code:

CT Cycle Time

BL Backlog

DD Demand

$\%>$ CT $\quad$ "Lateness Index": Percent of batches with cycle time exceeding a penalization treshold (default=20)

Performance Weighted average of normalized profit and $\%>C$ T values (weights being 1 and 2 respectively)

The parameters were set as follows in all runs:

\begin{tabular}{|c|c|c|c|c|}
\hline run length & & 5000 days & Constant & Constant number of incoming orders \\
\hline average orders received & ("demand") & 10 units per day & Step & $50 \%$ Increase in demand at day 50 \\
\hline productivity std. deviation & & 0.0 & Random & Randomized time series \\
\hline error processing delay & & 10.0 days & & of incoming orders \\
\hline penalty CT & & $20.0 \$$ & Spike & Extra pulse in demand of 20 at day 51 \\
\hline cost per hire & & $10.0 \$$ & & (i.e. demand triples to 30 on day 51) \\
\hline price & & $1.0 \$$ & Steady increase & Linear growth of \\
\hline wage & & $0.5 \$$ & & after day 50 \\
\hline averaging interval & & 5.0 days & Seasonal & Sine function of incoming orders \\
\hline
\end{tabular}

\section{Interpretation and Implications}

In the case of the step and the steady-growth environments (which we shall call "placid"), control is apparently needed to improve outcomes of both profit and CT. The maxima and the optima achieved with control are drastically better than those achieved without control. ${ }^{3}$ This

${ }^{3}$ We defined the maxima respectively as the highest levels of profits and the highest levels of timeliness expressed as the lowest percentages of batches delivered late (for those we shall use the notation " $\%>C \mathrm{CT}$ "). Optima are defined as the maxima (on a scale ranging from 0 to $100 \%$ ) of a combined performance on two dimensions (profit and timeliness) calculated on normalized values of profit and $\%>C T$, with weights of 1 and 2 , respectively. We emphasize that these weights can be changed according to the specific contexts in which the model is used. 
impressively visualizes the importance of feedback-driven control, which is one of the core concepts of the systems approach in general, and of cybernetics and system dynamics in particular. What about the unsteady environments, random and seasonal? In both cases, the maxima attained with control are lower than those attained without control. Hence, a merely profit-oriented stance would lead to the conclusion that no control at all is as good as or even better than any control. This reductionist view, however, is misleading. As soon as CT is included in the picture, the assessment changes completely. In the cases without control, not only in the unsteady, but also in the placid environments, the percentages of batches delivered late (in Table 2 denoted as $\%>C T$ ) ${ }^{4}$ are high and they can be reduced by control to a large extent.

Still, control is more difficult in the case of the former than in the case of the latter. To illustrate this, we have included a performance index under the three types of control for each environment examined. This is a weighted average of normalized values on profit and percentage of batches late, with weights of one and two, respectively..$^{5}$ The relatively higher performance values achieved in the placid environments result from the fact that in these the maxima achieved for profit and timeliness tend to coincide while in the case of unsteady environments, they exhibit a strong inclination to diverge. Also, the areas in which both profit and CT are acceptable are much larger in the case of the former than with the latter.

Interestingly enough, DD control even achieves surprisingly good results in the unsteady environments. However, as we had anticipated, these good results could only be achieved within very narrow bandwidths; that is, the outcomes were extremely sensitive to parameter misspecification. For example, "regulatory overkill," i.e., control gains set too high, can lead to a combination of spectacular success on timeliness, paired with dramatic losses on the profit side.

Generally, in the DD control mode, losses can far exceed the maximal achievable benefits, not only in the unsteady but even in the placid

${ }^{4}$ This measure is very important under the assumption that customers are sensitive to high cycle times. Therefore, in a performance measure combining profit and CT we have assigned a weight of 1 to the former and a weight of 2 to the latter (see footnote 3 and Table 2). We are also using the term "timeliness" as an approximation for low percentages of batches delivered late.

${ }^{5} \mathrm{We}$ are aware that this linear calculation is a simplification. In the future it should be refined, because in reality, low timeliness is likely to jeopardize revenue and profit in a nonlinear fashion. 
environments. This underlines the importance of extensive sensitivity analysis as well as parameter optimization in general, but particularly in the cases of random and seasonal environments. These aspects will be explored further in another paper.

A comparison of the three control modes concerning sensitivity and robustness leads to the conclusion that DD control is the most sensitive to parameter misspecification. CT control is the most robust, and BL control figures at an intermediate level of robustness. This ranking is straightforward with respect to the sensitivities of profit. Regarding the sensitivities of $\%>\mathrm{CT}$, the difference between the $\mathrm{CT}$ and $\mathrm{BL}$ control modes appears to be more subtle and therefore must be subjected to further investigation. In this section, we have not elaborated on the spike environment, but we shall revert to it in the next section, namely under Hypothesis 3.

\section{HYPOTHESES}

In this section, we shall explore some of the insights gained via the simulation runs, as summarized earlier, by testing a number of hypotheses related to the control of organizational processes.

In order to avoid a splitting up of the argumentation, this will be done in such a way that the hypotheses are exposed and then tested one by one. The list of hypotheses is not exhaustive, nor is it representative. However, each one of the hypotheses to be dealt with can be considered important. We have applied three criteria for their choice:

1. The hypothesis figures prominently in the literature.

2. The hypothesis is an important argument in the oral tradition of management practitioners or scientists.

3. The hypothesis is controversial or gets little attention despite its farreaching implications.

Our list is constituted only by hypotheses which fulfill at least two of these criteria. We shall test these hypotheses under the different environmental scenarios specified above. Given spatial limitations we cannot test each hypothesis under all of them, but we have to choose those scenarios which appear to be most appropriate for the case under study. Related limitations of conclusions derived from the tests will be pointed out. Results of additional tests are reported in Powell, Schwaninger, and Trimble (2001). 
Hypothesis 1. Stationarity of Input: The more unsteady the demand function, the lower the performance of the system. Also, the more placid the demand function, the higher the performance of the system.

This hypothesis is about the cost of adaptation, and it is espoused widely. Knut Bleicher, for example, one of the most influential writers on management in Europe, has analyzed the "adaptation gap" extensively (Bleicher, 1999).

Table 3 reads as follows: In the case of a scenario of randomized demand, the control gains were set at $\mathrm{P}=0.000125$ (labor force is adjusted with an amount of 0.000125 for each unit of the error signal) and $\mathrm{D}=0.4$ (labor force is adjusted with an amount of 0.4 for each unit of the first derivative of the error signal), for the cases in which the CT error signal was used in the experiments. The experiments where the standard deviation of the randomized demand function was set at $10 \%$ resulted in profits of $\$ 24,538$ (Table 3, top left) and $0 \%$ of batches delivered late (Table 3, bottom left), while in the case of a standard deviation of $30 \%$, profits shrank to $\$ 23,612$, and $0.3 \%$ of the batches showed late delivery. We tested Hypothesis 1 for the unsteady environments. Our simulations showed that both a growing variability of

Table 3. Simulation results under growing randomness

\begin{tabular}{|c|c|c|c|}
\hline \multicolumn{4}{|c|}{ A RancomDamand } \\
\hline \multicolumn{4}{|c|}{ Profit } \\
\hline Oontrd: & CT & $B$ & DD \\
\hline & $P=.00012 \overline{5}$ & $P=0005$ & $P=0.1$ \\
\hline Demand SD (\%) & $D=0.4$ & $D=0.8$ & $D=0.08$ \\
\hline 10 & 24538 & 24054 & 23603 \\
\hline 20 & 24075 & 23083 & 22205 \\
\hline 30 & 23612 & 22067 & 20809 \\
\hline 40 & 23154 & 21056 & 19450 \\
\hline 50 & 22788 & 20170 & 18240 \\
\hline 60 & 22569 & 19504 & 17253 \\
\hline 70 & 22508 & 19095 & 16481 \\
\hline 80 & 22604 & 18943 & 15889 \\
\hline 90 & 22806 & 18975 & 15428 \\
\hline 100 & 23136 & 19161 & 15080 \\
\hline
\end{tabular}

\begin{tabular}{|c|c|c|c|}
\hline \multicolumn{4}{|c|}{ B. Oxdic DamandPeriod 360} \\
\hline \multicolumn{4}{|c|}{ Proflt } \\
\hline Contra: & CT & $\overline{\mathbf{B L}}$ & $D D$ \\
\hline & $P=01$ & $P=01$ & $P=1$ \\
\hline & $D=0.5$ & $D=0.5$ & $D=0.5$ \\
\hline Amplitude & $i=0.00005$ & $T=0.00005$ & $1=0.00005$ \\
\hline 20 & 24081 & 24405 & 24546 \\
\hline 40 & 20766 & 21803 & 24090 \\
\hline 60 & 15679 & 17813 & 23610 \\
\hline 80 & 8506 & 13643 & 23130 \\
\hline 100 & 3910 & 9499 & 22681 \\
\hline
\end{tabular}

\begin{tabular}{|c|c|c|c|}
\hline \multicolumn{4}{|c|}{$\%>\mathrm{CT}$} \\
\hline Contrd: & CT & BL & DD \\
\hline & $P=.000125$ & $P=.0005$ & $P=1$ \\
\hline Demand SD (\%) & $D=0.4$ & $D=0.8$ & $D=0.08$ \\
\hline 10 & 0.0 & 0.0 & 0.0 \\
\hline 20 & 0.0 & 0.0 & 0.0 \\
\hline 30 & 0.3 & 0.0 & 0.0 \\
\hline 40 & 1.6 & 0.0 & 0.0 \\
\hline 50 & 3.1 & 0.0 & 1.2 \\
\hline 60 & 5.7 & 0.2 & 7.1 \\
\hline 70 & 9.0 & 0.5 & 15.8 \\
\hline 80 & 12.3 & 0.8 & 26.4 \\
\hline 90 & 15.4 & 1.2 & 33.0 \\
\hline 100 & 18.1 & 1.9 & 37.3 \\
\hline
\end{tabular}

\begin{tabular}{|r|l|l|l|}
\hline \multicolumn{5}{|c|}{$\%>C T$} \\
\hline Conkrd: & CT & BL & DD \\
\hline & $P=01$ & $P=01$ & $P=.1$ \\
\hline & $D=0.5$ & $D=0.5$ & $D=0.5$ \\
\hline Amplitude & $1=0.00005$ & $1=0.00005$ & $1=0.00005$ \\
\hline 20 & 7.5 & 0.0 & 0.0 \\
\hline 40 & 17.6 & 21.4 & 0.0 \\
\hline 60 & 25.2 & 26.6 & 0.0 \\
\hline 80 & 25.3 & 28.5 & 53.5 \\
\hline 100 & 24.5 & 28.4 & 76.6 \\
\hline
\end{tabular}


demand in the random environment as well as a growing amplitude of the demand cycle in the seasonal environment decrease profit and timeliness. Increasing randomness lowers profit most under BL control due to frequent changes in head count, but the result is a much better control of excess CT. Using CT control keeps profit high, but excess CT grows large. Using DD control degrades both profit and excess CT (see Table 3).

In the case of increased amplitude in the seasonal environment it is necessary to use an integral gain to assure stability. All three, CT-, BL-, and DD-based controls, can be used with different performances at distinct amplitudes (Table 3).

In summary, for the unsteady environments, Hypothesis 1 is supported.

The unanticipated result here is that the negative effects of randomness can be counterbalanced almost completely via BL control. We also stress how different the three control regimes are in terms of their robustness to randomness. Some pertinent clues have been given above, but we find that further inquiry is necessary in this respect.

Hypothesis 2. Interventions: 1. The lower the threshold at which an intervention takes place, the higher the performance of the system; 2. The higher the threshold at which an intervention takes place, the lower the performance of the system.

This hypothesis reflects the view that in situations of frequent changes (in our case represented by the random environment scenario) results will be better the more flexibly a system adapts. We have differentiated between two intervention thresholds, an upper and a lower control level (UCL versus LCL). Both were defined as minimum deviations of the error signal, at which adaptation would take place.

The tests for the random demand environment show that (see Table $4)^{6}$ in the case of UCL, profit does not change significantly with a decrease of the intervention threshold. However, we found a significant improvement on timeliness with a decrease of UCL. This corroborates Hypothesis 2. On the other hand, we found that increasing the LCL leads to significant improvements on timeliness, although this implies a certain sacrifice on the profit side. This in some sense represents "self-organizational" forces and it contradicts Hypothesis 2.

The conclusion is that UCL should be kept low and LCL high to optimize performance via a balance of intrinsic and extrinsic organization.

\footnotetext{
${ }^{6}$ In the case of the LCL variations, UCL was kept at zero and vice versa.
} 
Table 4. Outcomes with different control limits (UCL and LCL) — random demand

\begin{tabular}{|c|c|c|c|c|}
\hline \multirow[t]{10}{*}{ A. UCL } & & \multicolumn{2}{|r|}{ Profit } & \multirow[b]{2}{*}{$\begin{array}{l}\overline{D D} \\
F=02 \\
D=0.1\end{array}$} \\
\hline & $\begin{array}{l}\text { Control: } \\
\text { UCL }\end{array}$ & $\begin{array}{l}\mathrm{CT} \\
P=002 \\
D=0.08\end{array}$ & $\begin{array}{l}B L \\
P=.002 \\
D=0.08\end{array}$ & \\
\hline & & 24099 & 24228 & 22155 \\
\hline & & 24180 & 24305 & 22155 \\
\hline & & 24332 & 24432 & 22136 \\
\hline & & 24436 & 24521 & 22063 \\
\hline & & 24546 & 24598 & 21971 \\
\hline & & 24617 & 24649 & 21840 \\
\hline & & & $\% \times \mathrm{CT}$ & \\
\hline & $\begin{array}{l}\text { Control: } \\
\text { UCL }\end{array}$ & $\begin{array}{l}\text { CT } \\
P=002 \\
D=0.08\end{array}$ & $\begin{array}{l}B L \\
P=.002 \\
D=0.08\end{array}$ & $\begin{array}{l}D D \\
P=02 \\
D=0.1\end{array}$ \\
\hline . & & 10.9 & 6.3 & 11.5 \\
\hline & & 14.3 & 9.0 & 21.9 \\
\hline & & 21.2 & 16.1 & 61.0 \\
\hline & & 349 & 31.8 & 82.3 \\
\hline & & 55.9 & 53.6 & 90.6 \\
\hline & & 73.7 & 70.8 & 94.1 \\
\hline
\end{tabular}

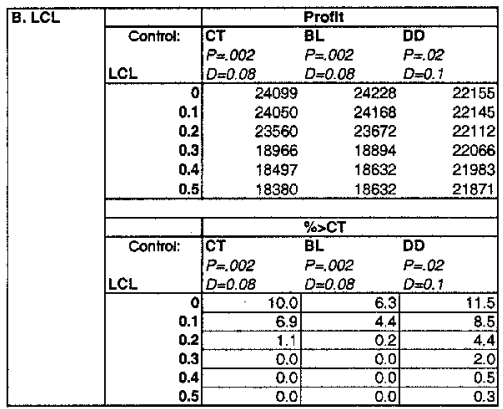

The somewhat counterintuitive rationale behind this conclusion is that if profit is not the sole criterion of success, it is effective to respond more slowly to situations in which the labor force exceeds minimum requirements (and the resulting cycle time is below the target) than it is to respond slowly when the labor force is below requirements. In other words, be quick to increase labor, but slow to reduce it. Of course, this conclusion depends entirely on the relative importance of profit and timeliness of delivery.

Hypothesis 3. Adaptation: Small deficits of adaptation have enduring negative impacts.

This hypothesis is related to the common-sense knowledge that present events impinge on the future. However, it also incorporates more sophisticated insights which have appeared under such labels as "the historicity of dynamical systems," "organizational ecology," and "the importance of initial conditions." Minimal differences in these can shape the trajectories of complex systems in completely distinct ways, as has been shown by chaos theory and complexity theory. In our observation we have focused on a specific aspect, which, in our opinion, concentrates most of this wisdom in a nutshell: The impact of action and of nonaction on the course of events.

Despite the abundance of pertinent literature, we would only like to emphasize two aspects here: the consequences of a lack of adaptation and the long term aspect of such consequences.

Our case in point is the run without control in the spike environment (see Table 5). Common-sense knowledge would strongly suggest that 
Table 5. The impact of different demand spikes on cycle time (5000 runs, no controls)

\begin{tabular}{lccccccc}
\hline $\begin{array}{l}\text { Size of } \\
\text { spike }(\%)\end{array}$ & $\begin{array}{c}\text { Pulse } \\
\text { multiplier }\end{array}$ & $\begin{array}{c}\text { Demand } \\
\text { multiplier }\end{array}$ & Profit & $\%>$ CT & $\begin{array}{c}\text { Average } \\
\text { CT }\end{array}$ & $\begin{array}{c}\text { Maximum } \\
\text { CT }\end{array}$ & $\begin{array}{c}\text { Std. dev. } \\
\text { CT }\end{array}$ \\
\hline 200 & 2 & 3 & 25,000 & 0.0 & 17.0 & 17.0 & 0.2 \\
300 & 3 & 4 & 25,000 & 0.0 & 18.0 & 18.0 & 0.3 \\
400 & 4 & 5 & 25,000 & 0.0 & 19.0 & 19.0 & 0.4 \\
500 & 5 & 6 & 25,000 & 0.0 & 19.9 & 20.0 & 0.5 \\
600 & 6 & 7 & 25,000 & 98.6 & 20.9 & 21.0 & 0.6 \\
\hline
\end{tabular}

even if no adaptation takes place, the average cycle time would first go up drastically, as a consequence of the extra pulse in demand, at time 51, but soon thereafter, it would even out at an average close to 15 . However, the results obtained show that average CT does not recede even after 5000 time periods: for a spike size of an additional 20 order units $(200 \%)$ at time $=51$ it stays at 17.0 , and for a spike of $60(600 \%)$ at 20.9 days. Although the percentage of orders delivered under the penalty threshold (20 days) remains at $0 \%$ until a spike size of $50(500 \%)$, it jumps to $98.6 \%$ at a spike size of $60(600 \%)$, because the penalty threshold is exceeded. This persistent increase in cycle time occurs because the onetime increase in demand never leaves the backlog, so all later arriving demands have to wait for more jobs to finish.

This instance shows clearly that the consequences of a lack of adaptation are tangible for much longer periods than intuition would suggest. It also supports the idea that not only wrong action can be fatal, but that the path from dearth of action to disaster can be short. Hypothesis 3 therefore is supported.

We have also tested to what extent control can deal with problems of this type. All three types of control-via the CT-, BL-, and DD-error signals - are suitable for dealing with spikes effectively. Figure 1 shows a comparison of the adaptive behaviors of the system in three cases, which correspond to the respective optima attained. The dynamic patterns exhibited visualize that the most elegant control is achieved by means of the DD controller. (Pertinent data are exhibited in Table 6.) However, we emphasize that this is only the case, if labor is controlled perfectly once the spike arrives (as shown in Figure 1).

However, if the controller would fail to respond perfectly, a backlog would build up. Then, the DD controller would be unable to recognize that problem and therefore fail to return the system to the desired state. 
C T Control

1: Measured Cycletime

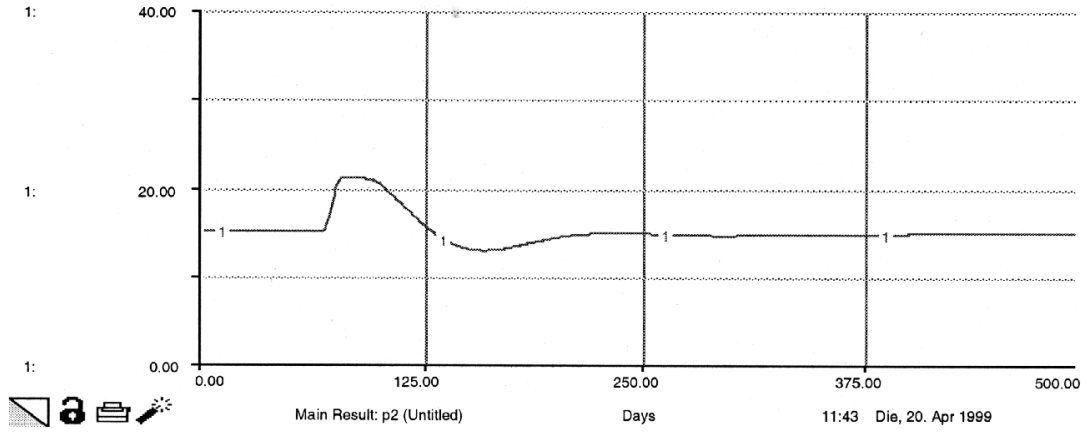

B L C ontrol
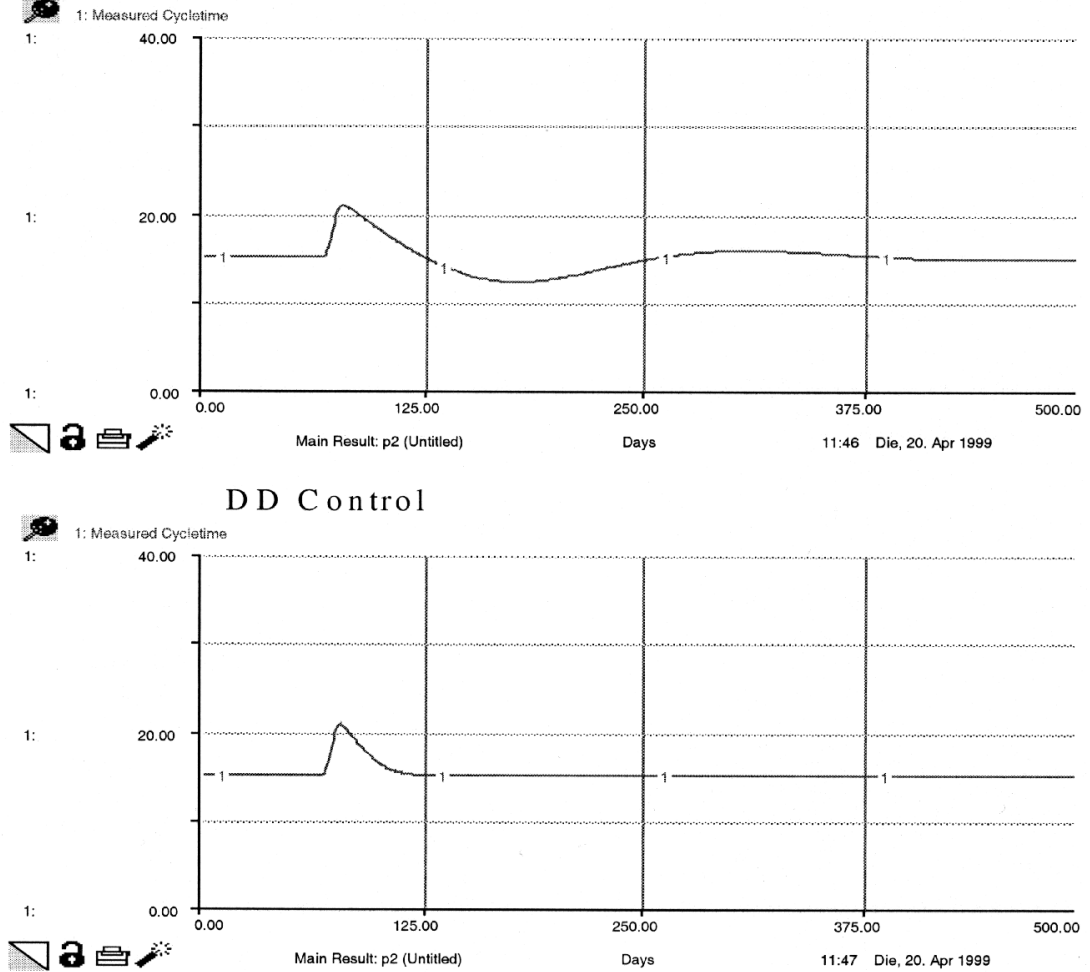

Figure 1. Adaptation as a function of different types of optimal control. 
Table 6. Data relative to Figure 1 (spike demand, 500 runs, with controls, for size of spikes $=600 \%$ )

\begin{tabular}{llllcccc}
\hline & & & & & Average \\
& P & D & Profit & $\%>$ CT & $\begin{array}{c}\text { Maximum } \\
\text { CT }\end{array}$ & $\begin{array}{c}\text { Std. dev. } \\
\text { CT }\end{array}$ \\
\hline CT Control & 0.0001 & 0.3 & 2,506 & 5.4 & 15.1 & 21.0 & 1.7 \\
BL Control & 0.005 & 0.2 & 2,510 & 2.4 & 15.0 & 21.0 & 1.6 \\
DD Control & 0.04 & 0.0025 & 2,506 & 1.4 & 15.3 & 21.0 & 1.0 \\
\hline
\end{tabular}

In contrast, the $\mathrm{CT}$ and the $\mathrm{BL}$ controller would respond: For the same basic setup (spike demand, 500 runs), however with $\mathrm{P}=0$ and $\mathrm{D}=0.05$, the $\%>C$ T attained were $11.0 \%$ for CT control, $8.0 \%$ for BL control, and $85.6 \%$ for DD control.

Hypothesis 4. Control Measures: In complex systems, balanced multidimensional control measures are more effective than unidimensional control measures.

Although this statement has become almost proverbial, it is very much neglected in practice. This has been demonstrated extensively by Reither's (1997) and Dörner's (1997) empirical studies.

Most of our experiments have incorporated quantitative adaptations of labor force. However, the model is also capable of representing changes in other parameters. One of those is technology, which can be represented - only to a limited extent - by the parameter of labor force productivity. There is clear evidence, that bidimensional adjustments increase performance more than unidimensional ones.

In Table 7, the results of two kinds of control strategies are compared, ${ }^{7}$ a) controls based on increasing average productivity (simply raising the value of the respective parameter) alone (left-hand side) and b) controls based on simultaneous adjustments of both head count (represented by changes in the $\mathrm{P}$ and $\mathrm{D}$ gains) and average productivity (righthand side). Only in the second case do we have closed-loop control, via adjustments of $\mathrm{P}$ and $\mathrm{D}$ as a function of gaps in CT performance. While the two approaches do only differ slightly in their profit outcomes, the differences in $\%>\mathrm{CT}$ (and therewith also in overall performance) are enormous. For additional evidence see footnote 11.

${ }^{7}$ Setting: seasonal demand environment, CT control, baseline value for average productivity $=1.0$. 
Table 7. Unidimensional versus bidimensional control (example for seasonal demand environment and CT control)

\begin{tabular}{|c|c|c|c|c|}
\hline \multirow{3}{*}{$\begin{array}{l}\text { Control for headcount: CT } \\
\text { Average productivity }\end{array}$} & \multicolumn{2}{|c|}{$\mathrm{P}=0, \mathrm{D}=0$} & \multicolumn{2}{|c|}{$\mathrm{P}=0.001, \mathrm{D}=0.00125$} \\
\hline & \multicolumn{4}{|c|}{ Outcome } \\
\hline & Profit & $\%>\mathrm{CT}$ & Profit & $\%>\mathrm{CT}$ \\
\hline 1.0 & 25,000 & 71.1 & 20,945 & 26.4 \\
\hline 1.5 & 33,333 & 71.1 & 30,508 & 25.6 \\
\hline 2.0 & 37,500 & 71.1 & 35,300 & 25.7 \\
\hline 5.0 & 45,000 & 71.1 & 43,861 & 22.5 \\
\hline 10.0 & 47,500 & 71.1 & 46,733 & 20.6 \\
\hline 12.0 & 47,760 & 0.0 & 47,492 & 9.8 \\
\hline 20.0 & 47,822 & 0.0 & 47,822 & 0.0 \\
\hline
\end{tabular}

In this context it must be emphasized that striving for multidimensional control opens actors to a broader view, which may lead to an extension of system boundaries and eventual reframing of the issues perceived. Transcending boundaries and reframing are essential traits of creative reflection, which fosters inventiveness and higher order learning.

These results support Hypothesis 4.

Furthermore, this example once again illustrates the importance and the effectiveness of closed-loop feedback control, the core concept around which Jay Forrester built the system dynamics methodology (Forrester 1961, 1968). If average productivity alone is used to "steer" the system, the result is too large a value of excess CT (71\% in Table 7), or it is minimum value (0), only achievable at extremely high levels of average productivity, which in reality may turn out illusory, i.e., nonachievable, or if achievable, result in excessive stress, being therewith counterproductive in human or social terms. However, if feedback control is applied (in this case CT control), relatively much better results can be obtained at more realistic levels of productivity.

Hypothesis 5. Time of Reaction: There is an inversely U-shaped relationship between time of reaction and performance of the system.

In other words, up to an optimal point, performance increases as a function of the frequency of (observations and) interventions based on observed deficits of performance, and then decreases.

We have examined this hypothesis from three aspects: 
1. averaging interval for cycle time,

2. staffing interval, and

3. error processing delay.

Our simulation experiments help ascertain the following patterns:

\section{Averaging Interval}

Variations of the averaging intervals for $\mathrm{CT}$ in the step and random demand environments reveal few control problems regardless of the controller used, up to an interval length of 10 to 15 time units (Table 8). However, with longer intervals it gets successively more difficult to control CT. The same observations apply to control based on backlog; nevertheless, it appears that a backlog controller is somewhat more robust to the averaging interval than is the CT controller. In the case of DD-based control the CT gets completely out of hand as the averaging interval increases. The reason is that a DD controller cannot "see" the buildup of work-in-process (WIP) in the system.

Averaging of observations is an almost universal aspect of modern business: most businesses do not have the manpower to measure and react to their performance on a daily or even weekly basis. Most businesses have a monthly or even quarterly reporting cycle. Our results here show that controlling a business process based on such averaging intervals using only arriving orders would be counterproductive or even

Table 8. Impact of variations in averaging intervals for CT

\begin{tabular}{|c|c|c|c|}
\hline \multicolumn{2}{|c|}{ A. Step Demand } & \multicolumn{2}{|l|}{ Profit } \\
\hline Control: & $\mathrm{CT}$ & BL & DD \\
\hline & $P=.002$ & $P=002$ & $P=.1$ \\
\hline Avg. Interval & $D=0.08$ & $D=0.08$ & $D=0.1$ \\
\hline 0 & 36917 & 37142 & 37189 \\
\hline 5 & 36882 & 37130 & 37185 \\
\hline 10 & 36831 & 37115 & 37182 \\
\hline 15 & 36773 & 37097 & 37181 \\
\hline 20 & 36706 & 37078 & 37181 \\
\hline 50 & 35986 & 36877 & 37175 \\
\hline 100 & 34153 & 35921 & 37116 \\
\hline \multicolumn{4}{|c|}{$\%>\mathrm{CT}$} \\
\hline \multirow[t]{2}{*}{ Gonlrd: } & CT & $B L$ & DD \\
\hline & $P=.002$ & $P=.002$ & $P=1$ \\
\hline Avg. Interval & $D=0.08$ & $D=0.08$ & $D=0.1$ \\
\hline 0 & 4.6 & 4.6 & 0.0 \\
\hline 5 & 4.6 & 4.6 & 0.0 \\
\hline 10 & 4.6 & 4.6 & 0.1 \\
\hline 15 & 4.6 & 4.6 & 0.3 \\
\hline 20 & 4.6 & 4.5 & 97.8 \\
\hline 50 & 19.6 & 4.5 & 98.4 \\
\hline 100 & 26.1 & 23.1 & 98.4 \\
\hline
\end{tabular}

\begin{tabular}{|c|c|c|c|}
\hline \multicolumn{2}{|c|}{ B. Random Demand } & \multicolumn{2}{|l|}{ Profit } \\
\hline Cantr: & $\mathrm{CT}$ & $B L$ & DD \\
\hline & $P=.002$ & $P=.002$ & $P=1$ \\
\hline Avg. Interval & $D=0.08$ & $D=0.08$ & $D=0.1$ \\
\hline 0 & 23767 & 23821 & 13260 \\
\hline 5 & 24099 & 24228 & 18991 \\
\hline 10 & 24146 & 24298 & 20055 \\
\hline 15 & 24146 & 24315 & 20730 \\
\hline 20 & 24129 & 24315 & 21374 \\
\hline 50 & 23953 & 24194 & 23749 \\
\hline 100 & 23574 & 23874 & 24203 \\
\hline & & & \\
\hline \multicolumn{4}{|c|}{$\%>\mathrm{CT}$} \\
\hline \multirow[t]{2}{*}{ Cantro: } & CT & BL & DD \\
\hline & $P=.002$ & $P=.002$ & $P=1$ \\
\hline Avg. Interval & $D=0.08$ & $D=0.08$ & $D=0.1$ \\
\hline 0 & 10.1 & 5.9 & 0.9 \\
\hline 5 & 10.9 & 6.3 & 3.2 \\
\hline 10 & 11.4 & 6.7 & 8.8 \\
\hline 15 & 12.1 & 7.4 & 12.9 \\
\hline 20 & 12.7 & 7.8 & 14.3 \\
\hline 50 & 15.4 & 12.1 & 14.3 \\
\hline 100 & 16.4 & 16.0 & 21.2 \\
\hline
\end{tabular}


disastrous. Doing so using CT might work fairly well, but the preferred approach would be to use backlog as the most effective measure of performance.

\section{Staffing Interval}

Increasing the staffing interval - the standard time span between changes in headcount - has essentially no impact with CT or BL controllers. The DD controller quickly becomes unstable with staffing intervals above 1

Table 9. Impact of variations in staffing intervals

\begin{tabular}{|c|c|c|c|}
\hline \multirow{2}{*}{$\begin{array}{l}\text { Step Demand } \\
\text { Control: }\end{array}$} & \multicolumn{3}{|c|}{ Profit } \\
\hline & CT & BL & DD \\
\hline Staffing int. & $\begin{array}{l}\mathrm{P}=.002 \\
\mathrm{D}=0.08\end{array}$ & $\begin{array}{l}\mathrm{P}=.002 \\
\mathrm{D}=0.08\end{array}$ & $\begin{array}{c}\mathrm{P}=.1 \\
\mathrm{D}=0.1\end{array}$ \\
\hline 1 & 36882 & 37130 & 37185 \\
\hline 2 & 36425 & 36884 & 37213 \\
\hline 3 & 36662 & 37015 & 37215 \\
\hline 4 & 36422 & 36884 & 37211 \\
\hline 5 & 35577 & 36974 & 37215 \\
\hline 10 & 36428 & 36888 & 37210 \\
\hline 15 & 36474 & 36911 & 37213 \\
\hline 20 & 36442 & 36888 & 37214 \\
\hline \multirow[t]{2}{*}{100} & 36486 & 36847 & 37064 \\
\hline & \multicolumn{3}{|c|}{$\%>C \mathrm{CT}$} \\
\hline Control: & CT & BL & DD \\
\hline & $\mathrm{P}=.002$ & $\mathrm{P}=.002$ & $\mathrm{P}=.1$ \\
\hline Staffing int. & $\mathrm{D}=0.08$ & $\mathrm{D}=0.08$ & $\mathrm{D}=0.1$ \\
\hline 1 & 4.6 & 4.6 & 0.0 \\
\hline 2 & 6.9 & 7.0 & 98.3 \\
\hline 3 & 5.8 & 5.9 & 0.3 \\
\hline 4 & 6.9 & 7.0 & 98.3 \\
\hline 5 & 6.2 & 6.3 & 0.5 \\
\hline 10 & 6.9 & 6.8 & 98.3 \\
\hline 15 & 6.6 & 6.9 & 98.3 \\
\hline 20 & 6.8 & 6.9 & 98.3 \\
\hline 100 & 6.7 & 6.9 & 98.4 \\
\hline
\end{tabular}


day (Table 9) for the same reasons cited above. When the staffing interval is longer than 1 day, this control scheme cannot react quickly enough to a change in the demand stream. The consequences are a buildup of WIP, which is invisible to the controller, and severe deterioration in CT.

\section{Error Processing Delay}

Error processing delays are controllable (i.e., they can be compensated) under CT or BL until they become large. In this case there seems no essential difference in effectiveness between the $\mathrm{CT}$ and BL controllers. Under DD, again, losses as well as delays become huge very easily (Table 10).

Altogether, reaction time, operationalized here in terms of averaging intervals, staffing intervals, and error processing delays, has an impact

Table 10. Impact of variations in error processing delays (EPD)

\begin{tabular}{|c|c|c|c|}
\hline \multirow{2}{*}{$\begin{array}{l}\text { Step demand } \\
\text { Control: }\end{array}$} & \multicolumn{3}{|c|}{ Profit } \\
\hline & CT & $\mathrm{BL}$ & DD \\
\hline & $\mathrm{P}=.002$ & $\mathrm{P}=.002$ & $\mathrm{P}=.1$ \\
\hline EPD & $\mathrm{D}=0.08$ & $\mathrm{D}=0.08$ & $\mathrm{D}=0.1$ \\
\hline 1 & 37018 & 37174 & 37240 \\
\hline 5 & 36965 & 37517 & 37236 \\
\hline 10 & 36882 & 37130 & 37185 \\
\hline 20 & 36627 & 37057 & 7674 \\
\hline 50 & 34638 & 36248 & -27108 \\
\hline \multirow[t]{2}{*}{100} & 26390 & 30819 & -76883 \\
\hline & \multicolumn{3}{|c|}{$\%>C T$} \\
\hline Control: & CT & $\mathrm{BL}$ & $\mathrm{DD}$ \\
\hline & $\mathrm{P}=.002$ & $\mathrm{P}=.002$ & $\mathrm{P}=.1$ \\
\hline EPD & $\mathrm{D}=0.08$ & $\mathrm{D}=0.08$ & $\mathrm{D}=0.1$ \\
\hline 1 & 4.6 & 4.7 & 0.0 \\
\hline 5 & 4.6 & 4.7 & 0.0 \\
\hline 10 & 4.6 & 4.6 & 0.0 \\
\hline 20 & 4.6 & 4.5 & 50.0 \\
\hline 50 & 23.9 & 21.6 & 55.1 \\
\hline 100 & 21.7 & 23.1 & 55.4 \\
\hline
\end{tabular}


with different facets, as our exploration has shown. Reaction time tends to turn control more difficult, as it becomes large. The U-shape expected by Hypothesis 5 is not a generally observable pattern, although it can be ascertained in some cases (e.g., in the seasonal demand environment, for profit, under CT and BL control, with increasing averaging interval, a Ushape can be ascertained).

In summary, almost all our results show that CT decreases as any of the averaging intervals increase, although in many cases that decrease is only weakly noticeable for a while. Profit also is either unchanged or declines. By and large, increasing averaging intervals hurts performance monotonically. Hypothesis 5 is to be revised.

Hypothesis 6. Maximization: If a system aims at maximizing one goal variable without making any other changes, it is likely to show unstable behavior (Adam 1985).

The hypothesis is intuitively applicable to all kinds of systems (see Kelly 1994). An individual that maximizes work at the cost of regeneration will sooner or later be exhausted. An organization that maximizes profit while neglecting social and ecological concerns, will lose legitimacy and sooner or later be in trouble. The hypothesis is even corroborated by our small model which merely depicts operational variables.

This can be shown cogently by going back to the overall results of our simulation experiments, presented in an earlier section. Table 11 gives an overview of the indices of overall performance achieved at those points where profit and $\%>\mathrm{CT}$ maxima were obtained. It can be seen that the points of maximum achievement in one dimension-profit or $\%>\mathrm{CT}$ - in some cases do also perform at a level of 1.00 (in other words, $100 \%$ of the overall performance measure, which is a composite of the achievements in both dimensions, profit and timeliness $(\%>\mathrm{CT})$, as specified in footnote 3 ), in others not. The maximum overall performance is possible in the step, the spike, and the steady increase environments. However, in the unsteady environments, these maxima are usually not attainable.

Exceptions in this case are the $98 \%$ performance of DD control in the random environment and the $100 \%$ performance of DD control in the seasonal environment for $\%>C T$. It must be noted that in both cases these high levels of performance were only achievable in a narrow "valley of opportunity," and therefore highly vulnerable to parameter misspecification. 
Table 11. Overall performance achieved at those points where profit and $\%>C T$ maxima are obtained ${ }^{a}$

\begin{tabular}{lccccc}
\hline Demand environments & Step & Random & Spike & Steady incr. & Seasonal \\
\hline CT Control & & & & & \\
$\quad$ Profit & 37,252 & 24,336 & 25,009 & 625,161 & 22,335 \\
Performance & 0.33 & 0.70 & 1.00 & 1.00 & 0.37 \\
$\%>$ CT & 4.6 & 3.1 & 0.0 & 3.8 & 19.7 \\
Performance & 0.98 & 0.92 & 1.00 & 1.00 & 0.67 \\
BL Control & & & & & \\
Profit & 37,258 & 24,374 & 25,009 & 625,928 & 22,347 \\
Performance & 0.83 & 0.62 & 1.00 & 1.00 & 0.35 \\
\% CT & 0.1 & 0.0 & 0.0 & 0.0 & 19.2 \\
Performance & 1.00 & 0.69 & 1.00 & 1.00 & 0.74 \\
DD Control & & & & & \\
Profit & 37,215 & 24,429 & 25,009 & 625,238 & 23,763 \\
Performance & 0.33 & 0.98 & 1.00 & 1.00 & 0.41 \\
\% $>$ CT & 0.0 & 1.2 & 0.0 & 0.0 & 0.0 \\
Performance & 1.00 & 0.98 & 1.00 & 1.00 & 1.00 \\
\hline
\end{tabular}

${ }^{a}$ Parameters set as specified in Table 2. For definition of the performance measure, see footnote 2 .

We have tested if the proposition of unstable behavior for systems where one variable is maximized holds. Figure 2 depicts the headcount function of a simulation run for the $\mathrm{CT}$ controller in a seasonal environment, with the proportional control gain at 0.000125 and the derivative control gain at 0.00125 . The cumulative profit achieved in this setting reaches the maximum value attainable with $\mathrm{CT}$ control, $22,335 .^{8}$ The cycling behavior of the CT time series - a form of relative instability - by and large shows bad performance in the timeliness dimension. No value inferior to a $\%>\mathrm{CT}$ of $36.6 \%$ is attained. However, better performance can be achieved, if additional controls are introduced (see also footnote 11).

${ }^{8}$ Under DD control, with $\mathrm{P}=0.016$ and $\mathrm{D}=0.32$, the profit maximum achieved is only a little higher, 23,763 , but at a cost of $\%>$ CT rising to 54.9 , and the pattern of CT being similar as in Figure 2. It must be added that CT can be brought under control if labor productivity is raised substantially. For example, $\%>$ CT can be reduced to the absolute minimum $(0 \%)$, with profit rising to 24,560 , if the productivity index is raised to 1.5 , with $\mathrm{P}=0.01$ and $\mathrm{D}=0.03$. This result again corroborates Hypothesis 4 . 


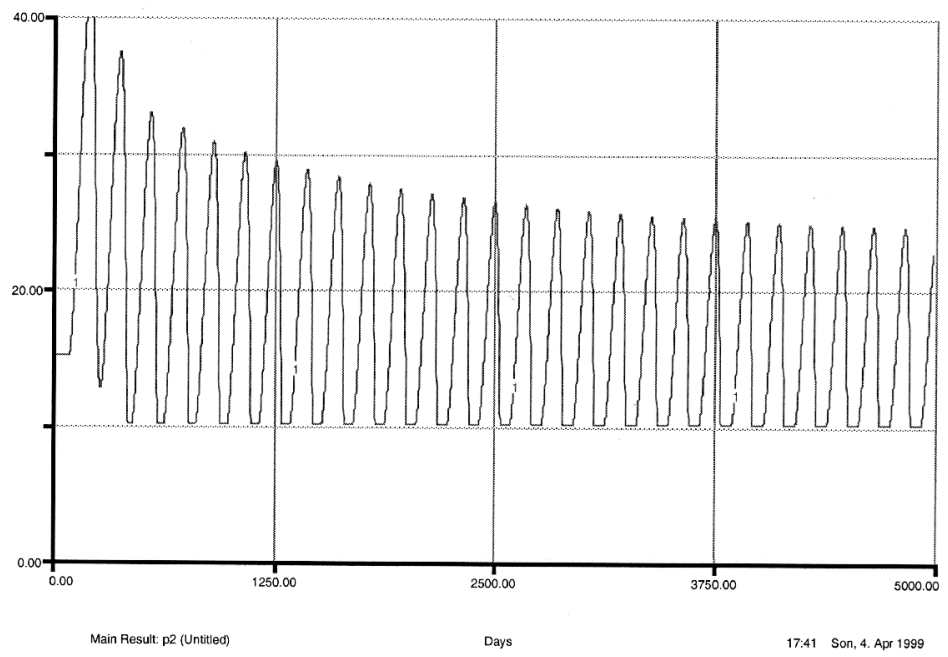

Figure 2. Cycling behavior (example).

In summary, Hypothesis 6 probably only applies to unsteady environments, in our case the random and seasonal ones. Systemic conjecture, however, strongly suggests that in more complex situations or systems than the ones modeled in the case at hand (e.g. business systems or ecological systems), Hypothesis 6 probably also holds for the placid environments. This aspect is to be explored further.

Hypothesis 7. Equifinality: In contrast to mechanical systems the same final state or goal may be reached from different initial conditions or via different pathways in organic systems (von Bertalanffy, 1968:132).

Bertalanffy's famous principle of equifinality, one of the landmarks of general systems theory, has not only been formulated at this very general level. It can also be ascertained in many different contexts, e.g., in situations of organization and leadership. One recent manifestation has been Levinthal's statement in the context of simulation studies of organizational "landscapes": "For complex entities, such as organizations, there are likely to be a number of local optima with nearly equivalent performance" (Levinthal 1997:948).

In Table 12, a small sample from our large database shows the profit outcomes of combinations of different control gains in the random 
Table 12. Outcomes of combinations of different control gains in the random demand environment (variability $=0.5$ )

\begin{tabular}{|c|c|c|c|}
\hline $\mathrm{CT}$ & $\mathrm{BL}$ & DD & Profit \\
\hline 0 & 0 & 0 & -22211 \\
\hline 0 & 0 & 0.05 & 24803 \\
\hline 0 & 0 & 0.1 & 24815 \\
\hline 0 & 0.1 & 0 & 20749 \\
\hline 0 & 0.1 & 0.05 & 24809 \\
\hline 0 & 0.1 & 0.1 & 24817 \\
\hline 0 & 0.5 & 0 & 13646 \\
\hline 0 & 0.5 & 0.05 & 24767 \\
\hline 0 & 0.5 & 0.1 & 24816 \\
\hline 0.006 & 0 & 0 & 6373 \\
\hline 0.006 & 0 & 0.05 & 24806 \\
\hline 0.006 & 0 & 0.1 & 24816 \\
\hline 0.006 & 0.1 & 0 & 13174 \\
\hline 0.006 & 0.1 & 0.05 & 24807 \\
\hline 0.006 & 0.1 & 0.1 & 24818 \\
\hline 0.006 & 0.5 & 0 & 9298 \\
\hline 0.006 & 0.5 & 0.05 & 24730 \\
\hline 0.006 & 0.5 & 0.1 & 24815 \\
\hline 0.01 & 0 & 0 & 10210 \\
\hline 0.01 & 0 & 0.05 & 24803 \\
\hline 0.01 & 0 & 0.1 & 24817 \\
\hline 0.01 & 0.1 & 0 & 7337 \\
\hline 0.01 & 0.1 & 0.05 & 24801 \\
\hline 0.01 & 0.1 & 0.1 & 24818 \\
\hline 0.01 & 0.5 & 0 & 8207 \\
\hline 0.01 & 0.5 & 0.05 & 24684 \\
\hline 0.01 & 0.5 & 0.1 & 24815 \\
\hline Statistics on profit range: & & Average & Variance \\
\hline For whole data set & & 19005.19 & 113554003.16 \\
\hline For subset of profits $>24,800$ & & 24811.73 & 38.07 \\
\hline
\end{tabular}

demand environment. This test embraces 27 combinations of the three control gains CT, BL, and DD (high, medium, and low, respectively). Fifteen (i.e., 56\%) of the profit outcomes reach the maximum value of $\$ 24,818$ or a value which is no more than 0.0685 percent lower than that maximum.

These output numbers corroborate the principle of equifinality (i.e., many ways to one and the same result). We have also found similar 
results in the case of other environments, and for optima of measures of performance combining profit and $\%>C$. In any one of the scenarios examined, the respective maxima or optima can be reached by a number of combinations of the control parameters. ${ }^{9}$ Therefore, Hypothesis 7 is supported by the results of our simulation experiments.

In this context, it must not be forgotten, that the saying "All roads lead to Rome" has a corollary, namely "All paths lead to hell," which can be considered a special case of Murphy's law. In other words, Hypothesis 7 not only applies to desirable, but also to undesirable states of a system. Our conclusion is that extensive and circumspect tests of sensitivities and vulnerabilities are crucial features of an effective control system.

\section{DISCUSSION}

Throughout the process of a) designing and testing the system dynamics model presented in this paper, b) examining the hypotheses which have orientated our work, and c) writing up this article, a complex web of insights has emerged. We are not coming up with completely new or revolutionary principles. By the way, as Chrétien de Malesherbes (1983) stated: "A new maxim is often a brilliant error."

What we have done was test some of the generally acknowledged principles for the control of complex systems, in the context of organizational process simulation. On these grounds we have come up with certain insights apt to trigger a better design of control mechanisms. The results we have achieved to date do in part underpin established principles, but in part they also challenge conventional wisdom.

We have examined seven hypotheses, most of which have been supported by our investigations. Several of them have only found partial support (Table 13). For example, Hypothesis 6 ("If a system aims at maximizing one goal variable without making any other changes, it is likely to show unstable behavior.") has been supported by our tests, but it only holds under the "ceteris paribus" clause, i.e., the condition of "all other things being equal." In other words, a) a scrutiny of the complexity of the situation or system at hand, and b) a questioning and eventual reconception of the goals, rules, constraints, and feedback structures driving the system may lead to different

\footnotetext{
${ }^{9}$ We have not further examined whether the numbers represent a series of multiple local optima or a number of data points near a single global optimum.
} 
Table 13. Overview of hypotheses examined and pertinent conclusions

Hypothesis Conclusions and insights from simulations

H1. Stationarity of input

The more unsteady the demand function, the lower the performance of the system. (Also, the more placid the demand function, the higher the performance of the system.)

\section{$\mathrm{H} 2$. Interventions}

2.1. The lower the threshold at which an intervention takes place, the higher the performance of the system.

2.2. The higher the threshold at which an intervention takes place, the lower the performance of the system.

\section{H3. Adaptation}

Small deficits of adaptation have enduring negative impacts.

\section{H4. Control measures}

In complex systems, balanced multidimensional control measures are more effective than unidimensional control measures.

\section{H5. Time of reaction}

There is an inversely U-shaped relationship between time of reaction and performance of the system.
- Supported, however tested only for the unsteady environments (random and seasonal)

- Overall, BL control is most effective

- Integral controller is necessary in the seasonal demand environment

- Tested only for the unsteady environments

- Supported only for UCL (upper control limit)

- Contradicted for LCL (lower control limit)

- Conclusively, changing UCL and LCL has different implications

- Recommendation: UCL treshold should be kept low and LCL threshold high

- Supported

- Timely control measures can effectively prevent long-term effects of short-term imbalances

- Lack of adaptation in the short term is unlikely to be compensated "automatically" in the long term

- Supported

- Striving for multidimensional control measures is also likely to enhance inventiveness and higher order learning

- The superiority of closed-loop feedback control to open-chain feedforward control is reiterated

- Not supported, except weak support in a few cases

- Modified to: By and large, increasing averaging intervals impairs performance monotonically

- Small observation intervals and fine-tuned adaptation are key levers for success 
Table 13. Continued.

Hypothesis

H6. Maximization

If a system aims at maximizing one goal variable without making any other changes, it is likely to show unstable behavior.

H7. Equifinality

In contrast to mechanical systems the same final state or goal may be reached from different initial conditions or via different pathways in organic systems.
Conclusions and insights from simulations

- Supported, however only for the unsteady environments

- In more complex situations than the one tested, the hypothesis may even hold for the placid environments

- In unsteady environments, maximizing one outcome variable is dangerous, in view of unintended side effects

- Supported for all types of environments

- The hypothesis applies also to undesirable states

- This highlights the importance of sensitivity and vulnerability analysis

conclusions. We would like to mention in this context, that Donella Meadows, an eminent systems thinker, who unfortunately passed away in 2001, devised a comprehensive theory of "Places to Intervene in a System" (Meadows 1997) that provides most insightful and valuable guidelines. Her solidly posited proposition is that quantitative and formal model-based reasoning alone remains rather ineffective. Meadows suggests that it must be embedded in an approach that considers and uses higher order levers such as the rules of the system (incentives, punishment, constraints), self-organization, the goals of the system, and finally the mindset or paradigm out of which goals, rules, and structures arise (see also Umpleby 1990).

Moving on from the discussion of the hypotheses examined, the situation gets more complex when different demand environments are compared. Some control systems are highly effective in certain environments but ineffective in others. Other control systems perform fairly well across many different environments. We have realized a crude ranking of the performance of the three controllers modeled under the five types of environments considered (Table 14).

The rankings show an overall superiority of DD control over BL control and of BL control over CT control. However, this applies more in terms of the precision than in terms of the robustness of the controllers. 
Table 14. Rankings of the performance of the different controllers across environments ${ }^{a}$

\begin{tabular}{lcccccccc}
\hline $\begin{array}{l}\text { Demand } \\
\text { environments }\end{array}$ & $\begin{array}{c}\text { Performance } \\
\text { indicator }\end{array}$ & Step & Random & Spike & $\begin{array}{c}\text { Steady } \\
\text { growth }\end{array}$ & Seasonal & $\begin{array}{c}\text { Horizontal } \\
\text { sum }\end{array}$ & $\begin{array}{c}\text { Overall } \\
\text { ranking }\end{array}$ \\
\hline CT Control & Total & 3 & 2 & 1 & 1 & 3 & 10 & 3 \\
& Profit & 3 & 1 & 1 & 3 & 2 & 10 & 3 \\
& $\%>\mathrm{CT}$ & 3 & 3 & 3 & 3 & 3 & 15 & 3 \\
BL Control & Total & 1 & 3 & 1 & 1 & 2 & 8 & 2 \\
& Profit & 1 & 1 & 1 & 1 & 3 & 7 & 1 \\
& $\%>\mathrm{CT}$ & 1 & 2 & 2 & 1 & 2 & 8 & 2 \\
DD Control & Total & 1 & 1 & 1 & 1 & 1 & 5 & 1 \\
& Profit & 1 & 3 & 1 & 2 & 1 & 8 & 2 \\
& $\%>\mathrm{CT}$ & 1 & 1 & 1 & 1 & 1 & 5 & 1 \\
\hline
\end{tabular}

${ }^{a}$ These rankings are based on the optima achieved as documented in Table 6 for spike demand, and in Table 2 for all other demand environments. The results for spike demand were taken from Table 6 due to more substantive conclusions that can be drawn from the experiments with the larger spikes.

BL and CT control are much more robust. ${ }^{10}$ The detailed comparison differentiated by dimensions of outcome are more ambiguous. In any case, more research will be needed here. Some provisional conclusions can be drawn for each control regime separately across all environments. The CT controller is incapable of achieving the maximal results in the unsteady environments. This is due to the time lag between the occurrence of a demand fluctuation and the measurement of CT. BL control performs relatively poorly in this sense in the seasonal and the random environments. This leads back to the fact that the BL controller is the slowest to react to fluctuations at the front end. Finally, DD performs well in all environments, because the pertinent feedback is most appropriate to coordinate market demand and the production system.

In this connection, it is necessary to broaden the picture. Our study is one of the basic investigative type. Even though the model at hand may be considered realistic, the control gain and the staffing change parameters in

${ }^{10}$ As we have shown, the DD controller works well only if a control gain is chosen that closely matches the incoming changes in demand. If not, the system goes haywire. Why then does the DD controller work at all? It works because the control measures are averaged, i.e., a step in actual demand is translated into a ramp in estimated demand. This gives a DD controller more than one change in demand to react to. So this is a case where averaging helps to make a not-too-good control scheme work well enough. 
the adjustment sector, as set now, are not subject to limitations as to the fine-tuning of the controllers. In future investigations the impact of a threshold that establishes a minimum of coarsegrainedness for changes in the labor force might lead to some surprising results. For example, some of the optima produced by the runs to date may turn out not to be realizable. ${ }^{11}$

It appears that the choice of a control system must depend to some extent on the type of demand environment that management expects to encounter, and on the trade-offs it makes between achieving acceptable performance and achieving superior performance, in different dimensions of outcome.

Finally, we would like to stress two further points which have emerged from our study:

1. The introduction of a proportional, a derivative, and an integral control gain into our model has proven highly useful and appears to be promising for the design of control systems. This feature is innovative, and to our knowledge such a loan from control theory has not been made before, for the control of organizational processes, in the sense elaborated here.

2. Once again, all of our work has shown closed-loop feedback control to be crucial for effective control systems. Also, in several instances (e.g., Hypotheses 2 and 6), the "counterintuitive behavior'" (Forrester 1971) of the system at hand has been brought out due to the use of system dynamics modeling and simulation.

Where do we go from here? We see three challenges that seem to point into new dimensions:

1. At the epistemological level of theory building: To date our study has operated at two levels. On a highly abstract level, we have tested very general hypotheses. On a highly concrete level, many simulation results have been generated. The exploration of these complementary issues should go further and lead to propositions of the midrange type. In several instances in this article, e.g., the comparison of different approaches to control in different environments, pertinent conclusions have been drawn in a provisional mode. We also have pointed out

${ }^{11}$ This will presumably be the case under DD-based control, which has proven to be most sensitive to parameter changes. 
aspects to be explored further, which should be tackled in future investigations.

2. At the technical level of model building: In this study, we have not dealt with parameter optimization, nor with time series analysis. In the future, more sophisticated aspects of control theory should be incorporated. It may, for example, be possible to optimize control measures or to calibrate them on the grounds of sophisticated time series analysis, and eventually Kalman filtering.

3. At the conceptual level of control systems design: As already outlined above, an extension of system boundaries would be desirable, e.g., to incorporate aspects of organizational strategy into the model used, and therewith to foster reframing and organizational learning. This would entail a modeling and embodiment of precontrols into the control systems, very much in the sense of the Meadows paper cited earlier (for specific organizational aspects of precontrol, see Schwaninger $(1993,2000))$. Crucial aspects insufficiently explored in the past are also the questions of how to build bridges between quantitative and qualitative modeling methods and between methodologies of the more positivistic and those of the more interpretative type, and between the technostructural and the procedural-discursive approaches to control (Schwaninger 1997).

The last aspect cited is very much a concern of the systems approach to management in general and to metamodeling in particular. Reframing is the key to effective metamodeling. But beyond that it is the first prerequisite to improving reality. Moreover, reframing needs both nourishment by creative, systemic thinking and validation by good models.

From a process perspective, a control system is to be designed not only to bring about what has been sought at the outset. It must also incorporate a heuristic to absorb epistemic progress and translate it into a self-referential process that triggers the (self-) improvement of the social system in focus. ${ }^{12}$

\section{REFERENCES}

Adam, A. 1985. Modellplatonismus und Computerorakel. In Die ganzheitlichverstehende Betrachtung der sozialen Leistungsordnung, Festschrift Josef Kolbinger, edited by W. Bühler et al. Vienna, New York: Springer.

\footnotetext{
${ }^{12}$ For further reading, see Gälweiler (1990) and Schwaninger (1989, 1994).
} 
Ashby, W. R. 1956. An introduction to cybernetics. London: Methuen.

Barlas, Y. 1996. Formal aspects of model Validity and validation in system dynamics. System Dynamics Review 12(3):183-210.

Bauer, A., J. Browne, R. Bowden, and J. Duggan. 1993. Shop floor control systems. From design to implementation. London: Chapman \& Hall.

Bleicher, K. 1999. Das Konzept. Integriertes Management, Vols. 1, 5, St. Galler Management-Konzept, Frankfurt, New York: Campus.

Conant, R., and W. R. Ashby. 1981. Every good regulator of a system must be a model of that system. In Mechanisms of intelligence. Ashby's writings on cybernetics, pp. 205-214, edited by R. Conant. Seaside, CA: Intersystems Publications.

Davenport, Th. H. 1993. Process innovation: Reengineering work through information technology. Boston: Harvard Business School Press.

de Malesherbes, ch.1983. Pensées et Maximes, mid-18th century. The Oxford book of aphorisms, p. 1. Oxford: Oxford University Press.

Dorner, D. 1997. The logic of failure: Recognizing and avoiding error in complex situations. Cambridge, MA: Perseus Press.

Dutta, S., and J.-F. Manzoni. 1999. Process re-engineering, organizational change and performance improvement. London: McGraw-Hill.

Espejo, R., W. Schuhmann, M. Schwaninger, and U. Bilello. 1996. Organizational transformation and learning. A cybernetic approach to management. Chichester, U.K.: Wiley.

Fairchild, A. 1998. Reengineering and restructuring the enterprise: A management guide for the 21st century. Charleston, SC: Computer Technology Research Corporation.

Forrester, J. W. 1961. Industrial dynamics. Cambridge, MA: MIT Press.

Forrester, J. W. 1968. Principles of systems. Cambridge, MA: MIT Press.

Forrester, J. W. 1971. Counterintuitive behavior of social systems. Technology Review 73(3):52-68.

Forrester, J. W., and P. M. Senge. 1980. Tests for building confidence in system dynamics models. In System dynamics, pp. 209-228, edited by A. A. Legasto, Jr., J. W. Forrester, and J. M. Lyneis. Amsterdam: NorthHolland.

Gälweiler, A. 1990. Strategische Unternehmensführung, 2d ed. Frankfurt, New York: Campus.

Geering, H. P. 1990. Mess- und Regelungstechnik, 2d ed. Berlin: Springer.

Gouillart, F. J., and J. N. Kelly. 1995. Transforming the organization. New York: McGraw-Hill.

Hammer, M., and J. Champy. 1993. Reengineering the corporation. A manifesto for business revolution. London: Nicholas Brealey.

Harvard Business Review. 1998. On measuring corporate performance. Boston: Harvard Business School Press. 
Hopp, W. J., and M. L. L. Spearman. 1996. Factory physics. Foundations of manufacturing management. Boston: Irwin McGraw-Hill.

Kaplan, R. S., and D. P. Norton. 1996. The balances scorecard. Boston: Harvard Business School Press.

Kelly, K. 1994. Out of control. London: Fourth Estate.

La Roche, U. 1994. A basic business loop as starting template for customized business-process-reengineering models, Proceedings, international system dynamics conference/change management, pp. 39-45. Stirling: University of Stirling.

La Roche, U., and M. Simon. 1998. Betriebserfahrung der Geschäftsführung effektiv nutzen. IO Management 12: 50-57.

Levinthal, D. A. 1997. Adaptation on rugged landscapes. Management Science 43(7):934-950.

Maciariello, J. A., and C. J. Kirby. 1994. Management control systems. Using adaptive system to attain control, $2 \mathrm{~d}$ ed., Englewood Cliffs, NJ: Prentice Hall.

Meadows, D. H. 1997. Places to intervene in a system. Whole Earth, Winter.

Denville, NJ: Point Foundation; (also http://www.wholeearthmag.com/ ArticleBin/109-html).

Österle, H. 1995. Business engineering, 2 vol. Berlin: Springer.

Powell, S. G., M. Schwaninger, and C. Trimble. 2001. Measurement and control of business processes. System Dynamics Review 17(1):63-91.

Reither, F. 1997. Komplexitätsmanagement. Munich: Gerling Akademie Verlag.

Schwaninger, M. 1989. Integrale Unternehmensplanung. Frankfurt, New York: Campus.

Schwaninger, M. 1993. A concept of organizational fitness. In Organizational fitness - Corporate effectiveness through management cybernetics, pp. 39-66, edited by R. Espejo and M. Schwaninger. Frankfurt, New York: Campus.

Schwaninger, M. 1994. Managementsysteme. Frankfurt, New York: Campus.

Schwaninger, M. 1997. Integrative systems methodology: Heuristic for requisite variety. International Transactions in Operational Research 4(4):109-123.

Schwaninger, M. 2000. Managing complexity - The path towards intelligent organizations. Systemic Practice and Action Research 13(2):207-241.

Sinatra, A., and A. Bhambri, eds. 1997. Corporate transformation. Norwell, MA: Kluwer Academic.

Umpleby, S. A. 1990. Strategies for regulating the global economy. Cybernetics and Systems: An International Journal 21:99-108.

Van Gigch, J. P. 1991. System design modeling and metamodeling. New York, London: Plenum Press.

Von Bertalanffy, L. 1968. General system theory, rev. ed. New York: Braziller. 


\section{APPENDIX A: DOCUMENTATION OF THE ITHINK MODEL AND THE SIMULATION INTERFACE}

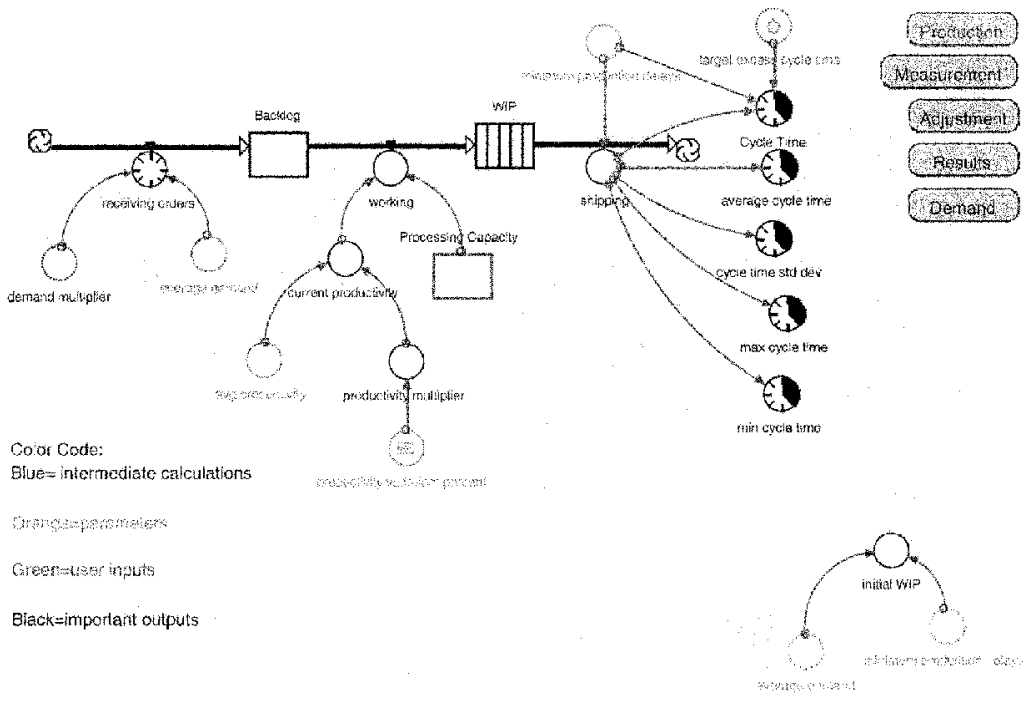

Figure 3. Model: production sector.
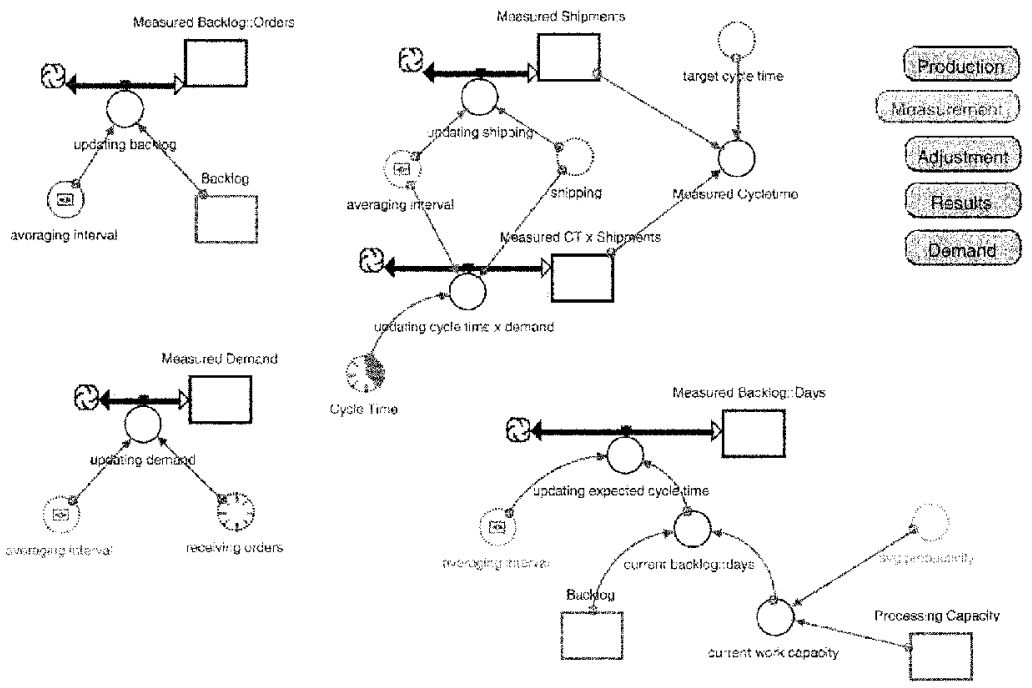

Figure 4. Model: measurement sector. 


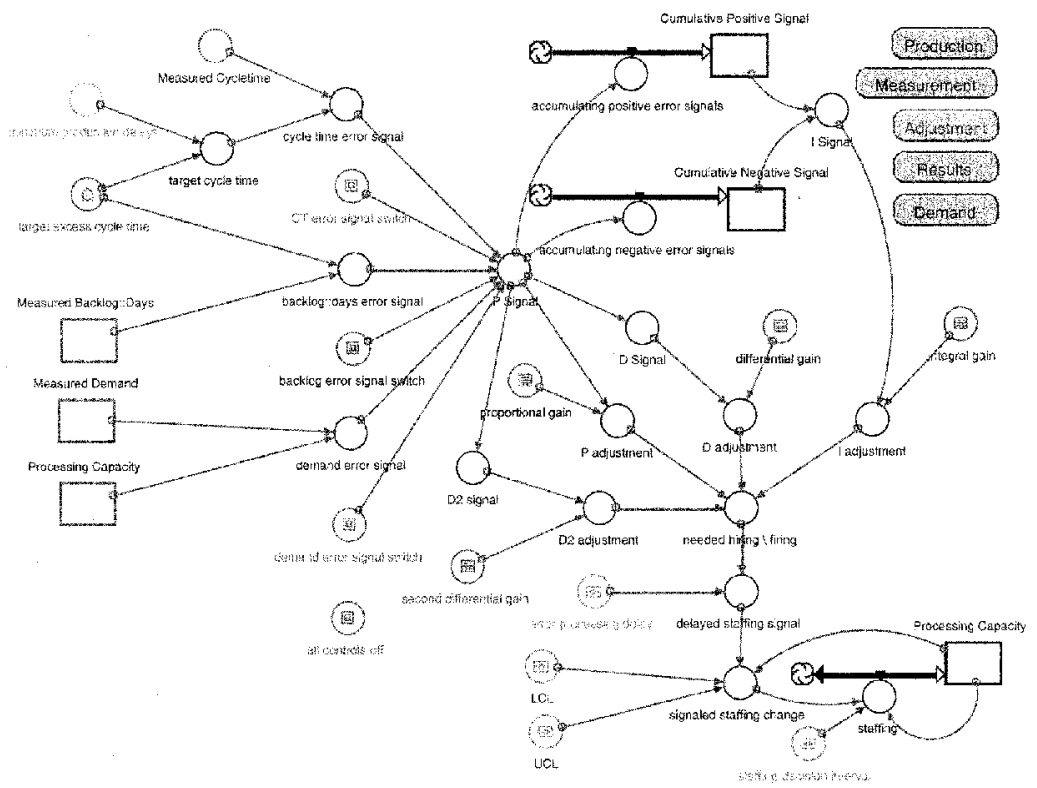

Figure 5. Model: Adjustment sector.
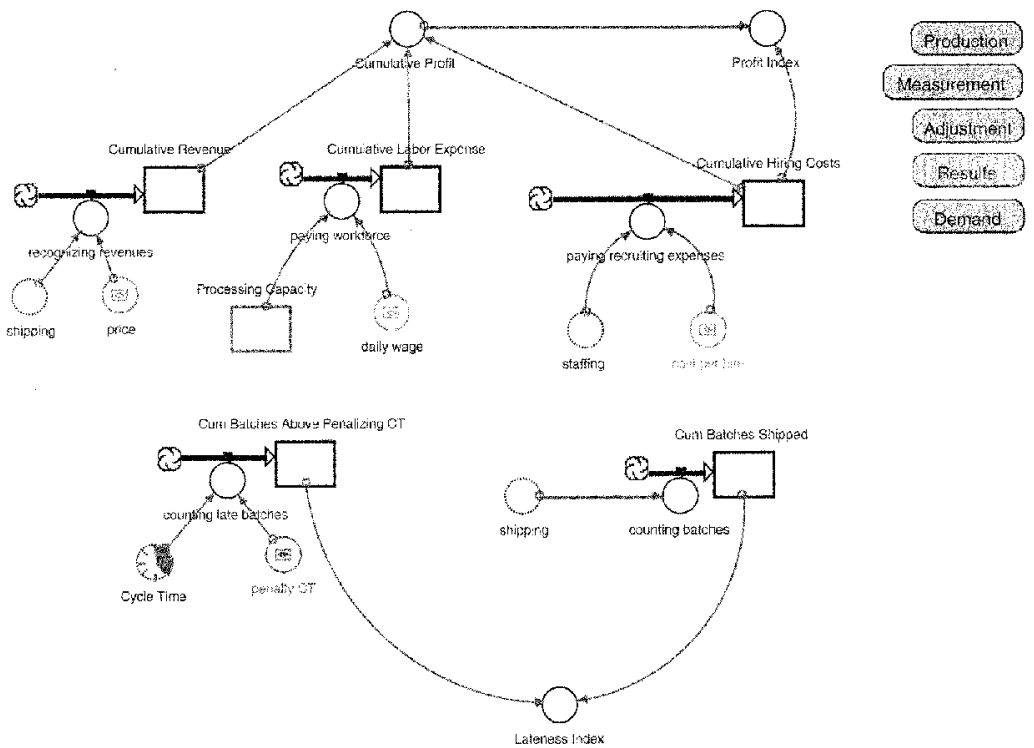

Figure 6. Model: Results sector. 


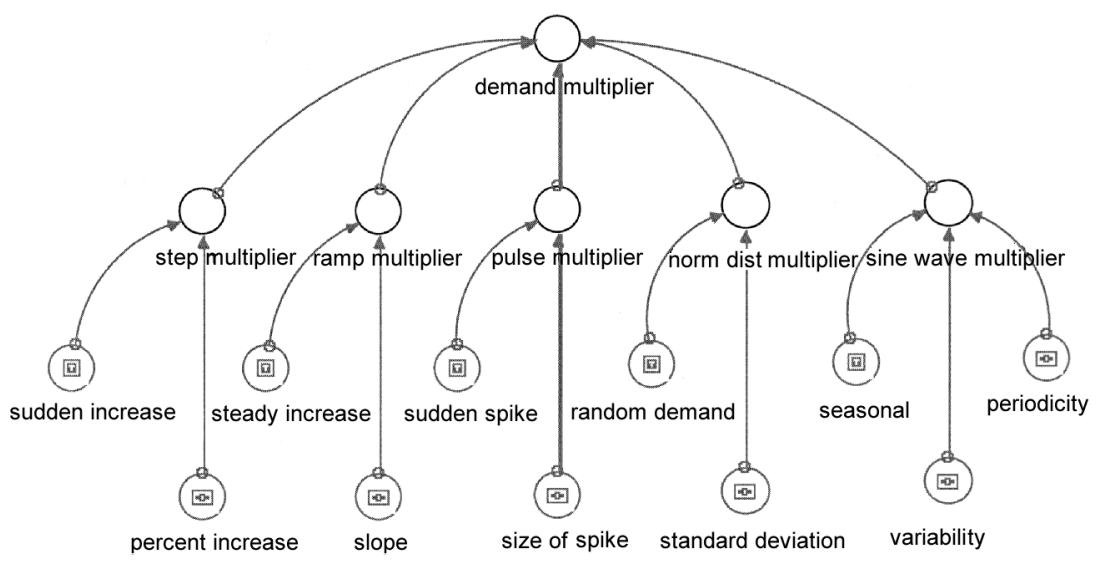

Figure 7. Model: Demand generator.

\section{Underlying Equations}

\section{Production Sector}

Backlog:

Backlog $(\mathrm{t})=$ Backlog $(\mathrm{t}-\mathrm{dt})+$ (receiving_orders-working $) * \mathrm{dt}$ INIT Backlog $=$ average_demand*target_excess_cycle_time INFLOWS:

receiving_orders $=$ average_demand*demand_multiplier OUTFLOWS:

working $=$ Processing_Capacity*current_productivity

WIP:

$\mathrm{WIP}(\mathrm{t})=\mathrm{WIP}(\mathrm{t}-\mathrm{dt})+($ working - shipping $) * \mathrm{dt}$

INIT WIP $=$ initial_WIP

TRANSIT TIME $=$ varies

INFLOW LIMIT $=$ INF

CAPACITY $=$ INF

INFLOWS:

working $=$ Processing_Capacity*current_productivity OUTFLOWS:

shipping $=$ CONVEYOR OUTFLOW

TRANSIT TIME = minimum_production_delays

Parameters \& Relationships:

average_cycle_time $=$ CTMEAN(shipping, 0,1$)$ 
average_demand $=10$

avg_productivity $=1$

current_productivity $=$ avg_productivity*(if time $<=50$ then 1 else productivity_multiplier)

Cycle_Time $=$ CYCLETIME(shipping, 1 ,target_excess_cycle_ time ${ }^{+}$minimum_production_delays)

cycle_time_std_dev $=$ CTSTDDEV(shipping, 1,0$)$

initial_WIP $=$ average_demand*minimum_production_delays

max_cycle_time $=$ CTMAX $($ shipping $, 0,0)$

minimum_production_delays $=10$

min_cycle_time $=\mathrm{CTMIN}($ shipping $, 0,0)$

productivity_multiplier $=$ RANDOM $(1-$

productivity_variation::percent /100,1 + productivity_variation::percent / 100)

productivity_variation::percent $=0$

\section{Measurement Sector}

Measured Backlog:

Measured_Backlog::Days $(\mathrm{t})=$ Measured_Backlog::Days $(\mathrm{t}-\mathrm{dt})+$ (updating_expected_cycle_time) $* \mathrm{dt}$

INIT Measured_Backlog::Days $=$ Backlog/working INFLOWS:

updating_expected_cycle_time $=$ (current_backlog::daysdelay(current_backlog::days,averaging_interval)) /averaging_interval Measured_Backlog::Orders $(\mathrm{t})=$ Measured_Backlog::Orders $(\mathrm{t}-\mathrm{dt})+$ (updating_backlog) $* \mathrm{dt}$

INIT Measured_Backlog::Order s $=$ average_demand* target_excess_cycle_time

INFLOWS:

updating_backlog $=($ Backlog-Delay $($ Backlog, averaging_interval $)) /$ averaging_interval

Measured CT x Shipments

Measured_CT_x_Shipments $(\mathrm{t})=$ Measured_CT_x_Shipment $\mathrm{s}(\mathrm{t}-\mathrm{dt})+$ (updating_cycle_time_x_demand) $* \mathrm{dt}$

INIT Measured_CT_x_Shipment $s=$ (minimum_production_delays + target_excess_cycle_time)* average_demand INFLOWS: 
updating_cycle_time_x_demand $=($ Cycle_Time*shippingdelay (Cycle_Time,averaging_interval)*delay(shipping , averaging_interval))/averaging_interval

Measured Demand:

Measured_Demand $(\mathrm{t})=$ Measured_Demand $(\mathrm{t}-\mathrm{dt})+($ updating_demand $)$ $* \mathrm{dt}$

INIT Measured_Demand $=$ average_demand INFLOWS:

updating_shipping $=$ (receiveing_orders-Delay(receiving_orders, averaging_interval))/averaging_interval

Measured Shipments:

Measured_Shipments $(\mathrm{t})=$ Measured_Shipments(t-dt) + (updating_shipping) $* \mathrm{dt}$

INIT Measured_Shipments $=$ average_demand INFLOWS:

updating_shipping $=($ shipping-Delay $($ shipping,averaging_interval $)) /$ averaging_interval

Parameters \& Relationships:

averaging_interval $=5$

current_backlog::days $=$ Backlog/current_work_capacity

current_work_capacity $=$ Processing_Capacity $*$ avg_productivity Measured_Cycletime $=$ if Measured_Shipments $=0$ then target_cycle_ time else

Measured_CT_x_Shipments /(Measured_Shipments)

\section{Adjustment Sector}

Cumulative Negative Signal:

Cumulative_Negative_Signal $(\mathrm{t})=$ Cumulative_Negative_Signal $(\mathrm{t}-\mathrm{dt})+$ (accumulating_negative_error_signals) $* \mathrm{dt}$

INIT Cumulative_Negative_Signa $1=0$

INFLOWS:

accumulating_negative_error_signals $=-\mathrm{P} \_$Signal

Cumulative Positive Signal:

Cumulative_Positive_Signal $(\mathrm{t})=$ Cumulative_Positive_Signal $(\mathrm{t}-\mathrm{dt})+$ (accumulating_positive_error_signals )* dt

INIT Cumulative_Positive_Signal $=0$ 


\section{INFLOWS:}

accumulating_positive_error_signals $=P$ P_Signal

Processing Capacity:

Processing_Capacity $(\mathrm{t})=$ Processing_Capacity $(\mathrm{t}-\mathrm{dt})+($ staffing $) * \mathrm{dt}$ INIT Processing_Capacity $=$ average_demand $/$ avg_productivity INFLOWS:

staffing $=$ if abs(time/staffing_decision_intervalint(time/staffing_decision_interval) $<\mathrm{dt} / 2 /$ staffing_decision_interval then max(signaled_staffing_change, 1 -

Processing_Capacity) else 0

Parameters and Relationships:

all_controls_off $=0$

backlog::days_error_signal = Measured_Backlog::Days-

target_excess_cycle_time

backlog_error_signal_switch $=0$

CT_error_signal_switch $=0$

cycle_time_error_signal $=$ Measured_Cycletime-target_cycle_time

D2_adjustment $=$ second_differential_gain*D2_signal

D2_signal $=$ DERIVN $($ P_Signal, 2$)$

delayed_staffing_signal $=$ DELAY(needed_hiring_l_firing,

error_processing_delay)

demand_error_signal $=$ Measured_Demand-Processing_Capacity

demand_error_signal_switch $=0$

differential_gain $=0.1$

D_adjustment $=$ differential_gain*D_Signal

D_Signal $=$ DERIVN $($ P_Signal, 1$)$ error_processing_dela $y=10$

error_processing_delay $=10$

integral_gain $=0.1$

I_adjustment $=$ integral_gain*I_Signal

I_Signal $=$ Cumulative_Positive_Signal-Cumulative_Negative_Signal

$\mathrm{LCL}=0$

needed_hiring_L_firing $=$ D_adjustment + I_adjustment +

$\mathrm{P} \_$adjustment $+\mathrm{D} 2$ _adjustment

proportional_gain $=0.1$

$\mathrm{P} \_$adjustment $=$proportional_gain*P_Signal

P_Signal $=$

backlog::days_error_signal * backlog_error_signal_switch +

CT_error_signal_switch*cycle_time_error_signal + demand_ 
error_signal*demand_error_signal_switch

second_differential_gain $=0$

signaled_staffing_change $=$ if delayed_staffing_signal/

Processing_Capacity $<\mathrm{UCL} / 100$ and

delayed_staffing_signal/Processing_Capacity $>$-LCL/100 then 0 else $\min (10000$,delayed_staffing_signal)

staffing_decision_interval $=1$

target_cycle_time $=$ minimum_production_delays +

target_excess_cycle_time

target_excess_cycle_time $=5$

$\mathrm{UCL}=0$

\section{Results Sector}

Cumulative Hiring Costs:

Cumulative_Hiring_Costs $(\mathrm{t})=$ Cumulative_Hiring_Costs $(\mathrm{t}-\mathrm{dt})+$

(paying_recruiting_expenses $) * \mathrm{dt}$

INIT Cumulative_Hiring_Cost $\mathrm{s}=0$

INFLOWS:

paying_recruiting_expenses $=$ if staffing $>0$ then cost_per_hire*staffing else 0

Cumulative_Labor_Expense $(\mathrm{t})=$

Cumulative_Labor_Expense $(\mathrm{t}-\mathrm{dt})+$ (paying_workforce $) * \mathrm{dt}$

INIT Cumulative_Labor_Expens e $=0$

INFLOWS:

paying_workforce $=$ Processing_Capacity*daily_wage

Cumulative Revenue:

Cumulative_Revenue $(\mathrm{t})=$ Cumulative_Revenue $(\mathrm{t}-\mathrm{dt})+$

(recognizing_revenues $) * \mathrm{dt}$

INIT Cumulative_Revenue $=1$

INFLOWS:

recognizing_revenues $=$ shipping*price

Cum Batches Above Penalizing CT:

Cum_Batches_Above_Penalizing_CT $(\mathrm{t})=$

Cum_Batches_Above_Penalizing_CT(t-dt) +

(counting_late_batches) $* \mathrm{dt}$

INIT Cum_Batches_Above_Penalizing_C T $=0$ 


\section{INFLOWS:}

counting_late_batches $=$ if Cycle_Time $>$ penalty_CT then 1 else 0

Cum Batches Shipped:

Cum_Batches_Shipped $(\mathrm{t})=$ Cum_Batches_Shipped $(\mathrm{t}-\mathrm{dt})+$ (counting_batches) $* \mathrm{dt}$

INIT Cum_Batches_Shipped $=0$

\section{INFLOWS:}

counting_batches $=$ IF time $>50$ and shipping $>0$ then 1 else 0

cost_per_hire $=10$

Cumulative_Profit $=$ Cumulative_Revenue-Cumulative_Labor_Expense-

Cumulative_Hiring_Costs

daily_wage $=0.5$

Parameters \& Relationships:

Lateness_Index $=\operatorname{IF}($ Time $>50)$ and Cum_Batches_Shipped $>0$

THEN(Cum_Batches_Above_Penalizing_CT /

Cum_Batches_Shipped)*100 ELSE 0

penalty_CT $=20$

price $=1$

Profit_Index $=$ Cumulative_Profit/(Cumulative_Hiring_Costs + Cumulative_Profit)

\section{Demand Generator}

Parameters \& Relationships:

demand_multiplier $=1+($ IF time $<=50$ then 0 else

norm_dist_multiplier + pulse_multiplier + ramp_multiplier +

sine_wave_multiplier + step_multiplier)

norm_dist_multiplier + normal(0,standard_deviation /

100,99999)*random_demand

percent_increase $=50$

periodicity $=180$

pulse_multiplier $=$ pulse(size_of_spike $/ 100,51$,stoptime)*sudden_spike

ramp_multiplier $=$ RAMP(slope $/ 100,50) *$ steady_increase

random_demand $=0$

seasonal $=1$

sine_wave_multiplier $=$ variability $/ 100 * \sin ($ time- 50$) * 2 * 3.1416 /$

periodicity)*seasonal

size_of_spike $=200$ 
slope $=1$

standard_deviation $=50$

steady_increase $=0$

step_multiplier $=$ STEP(percent_increase $/ 100,50) *$ sudden_increase sudden_increase $=0$

sudden_spike $=0$

variability $=50$

\section{Step 1--Select Pattern of Demand}
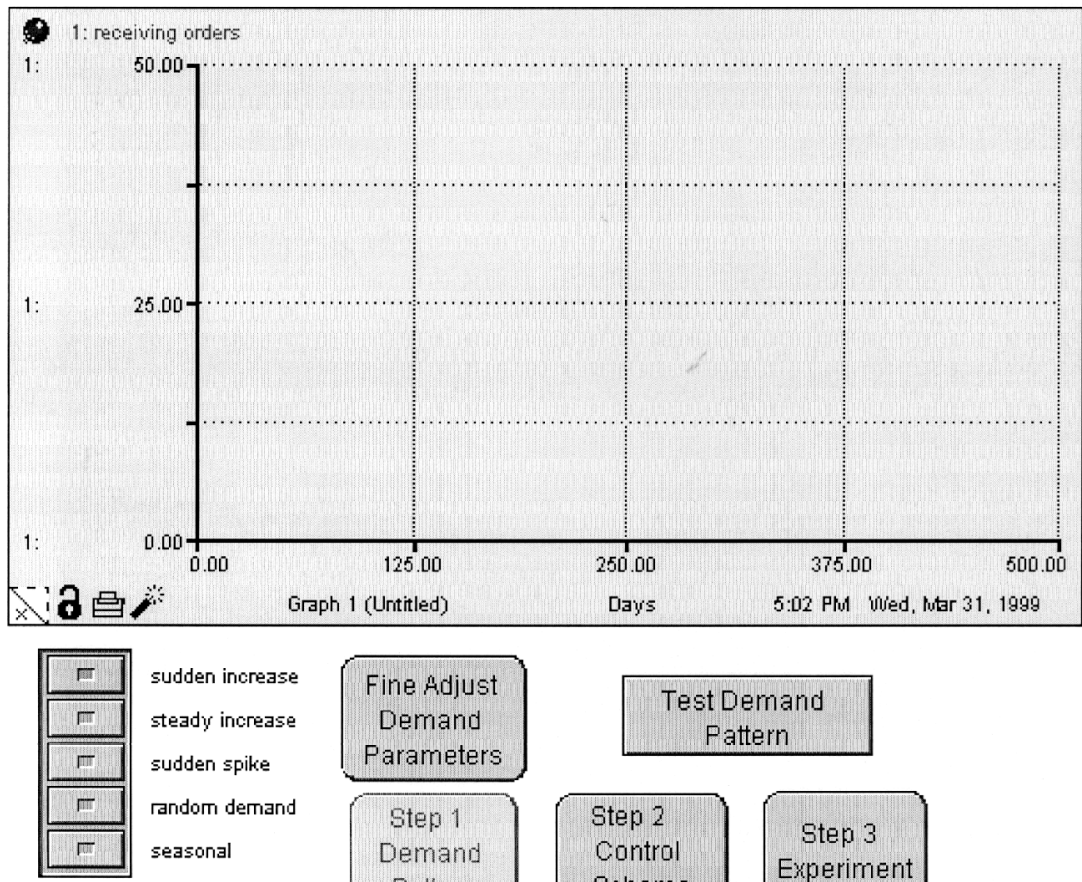

sudden increase steady increase sudden spike random demand seasonal

\section{Fine Adjust Demand Parameters}

Step 1
Demand
Pattern

\section{Test Demand}

Pattern

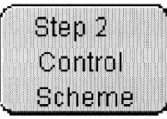

\section{Step 3} Experiment

Figure 8. Simulation interface: Select demand pattern. 
1. Sudden Increase -- Size of sudden jump in demand $(\%)$

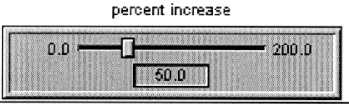

II. Steady Increase -- Rate of increase ( $\%$ of original demand per month.)

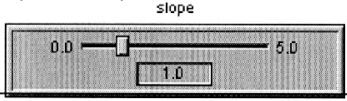

III. Sudden Spike -- Size of sudden demand spike ( $\%$ of normal monthly demand)

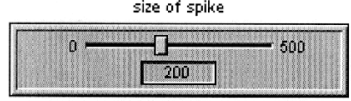

IV Normal Distribution--Standard Deviation of

Monthly Demand ( $\%$ of normal demand) standard deviation

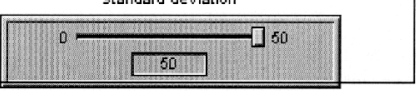

V. Seasonal--Size of Variation ( $\%$ of normal), \& Periadicity (days)

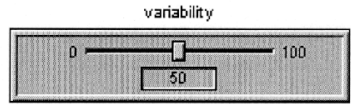

periodicity

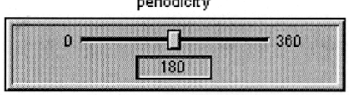

Done

Making

Adjustments

Figure 9. Simulation interface: Fine adjust demand parameters.

Step 2--Establish Control System

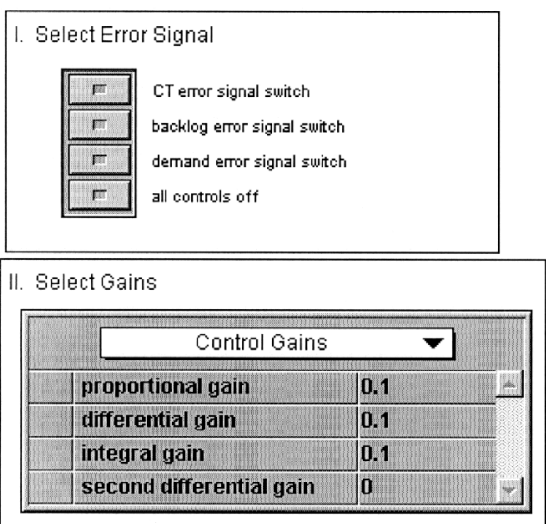
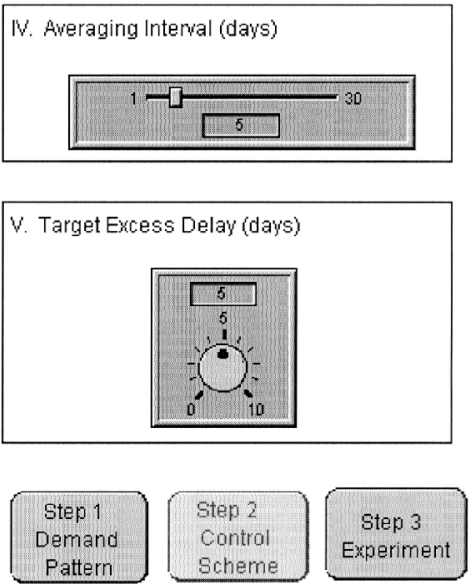

Figure 10. Simulation interface: Establish control scheme. 


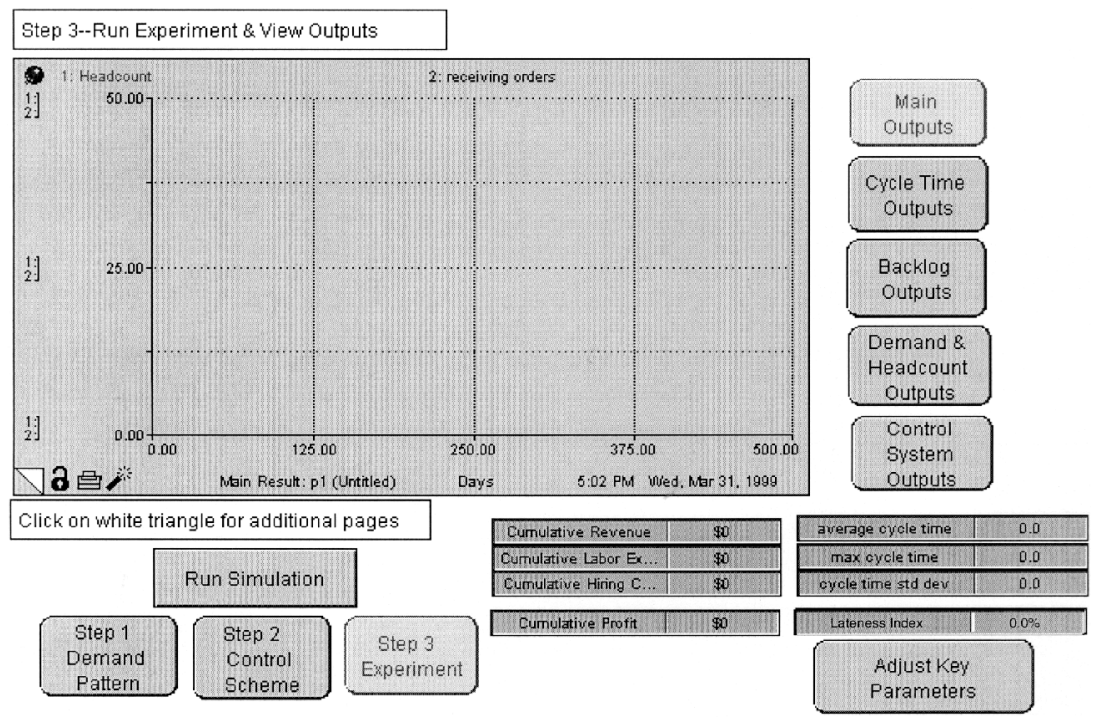

Figure 11. Simulation interface: Run simulation and view outputs.

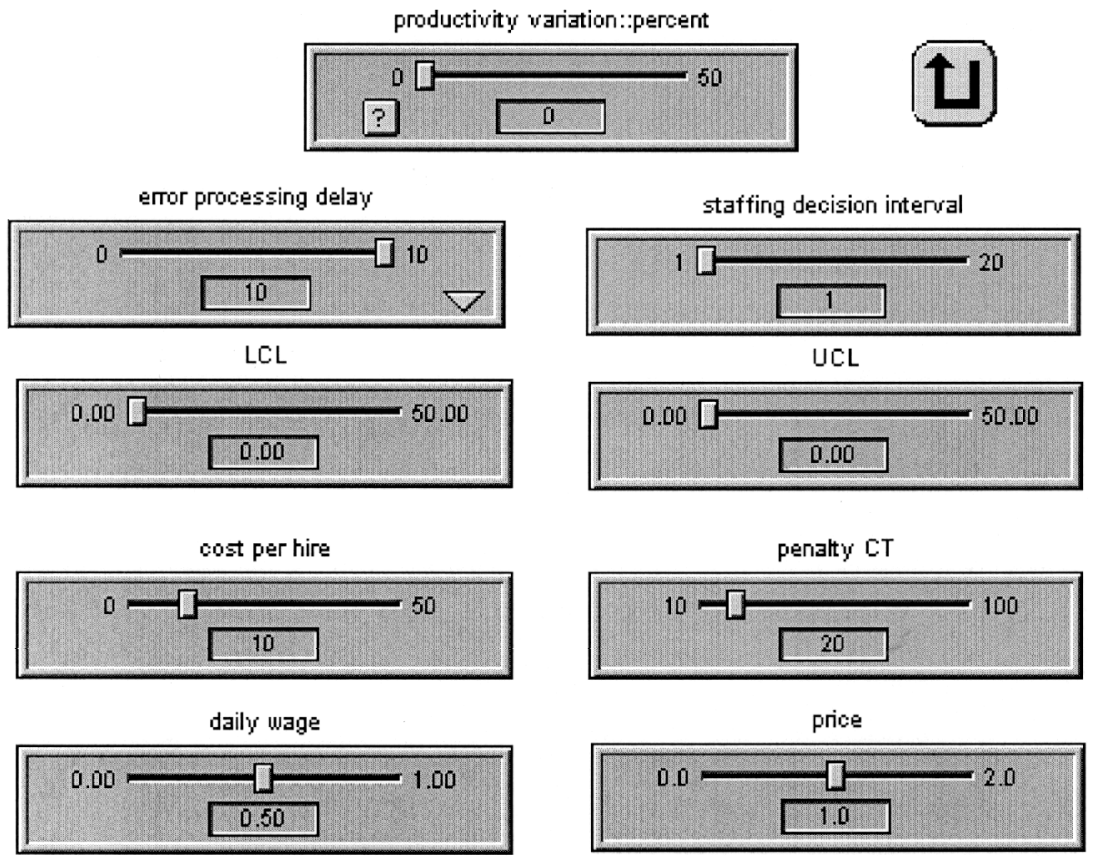

Figure 12. Simulation interface: Adjust key parameters. 


\section{APPENDIX B: QUICK REFERENCE FOR ABBREVIATIONS}

Table 15. Quick reference for abbreviations

\begin{tabular}{|c|c|c|}
\hline Abbreviation & Full name & Specification \\
\hline $\mathrm{BL}$ & Backlog & Measured in units/day \\
\hline CT & Cycle time & Measured in days \\
\hline DD & Demand & Received orders, measured in units/day \\
\hline$\%>\mathrm{CT}$ & Lateness index & $\begin{array}{l}\text { Percentage of batches delivered late, i.e., with cycle } \\
\text { time exceeding a penalization threshold (default } \\
=20 \text { days) }\end{array}$ \\
\hline EPD & Error processing delay & $\begin{array}{l}\text { Standardized delay for the correction of errors, } \\
\text { measured in days (default }=10 \text { ) }\end{array}$ \\
\hline $\mathrm{SD}$ & Standard deviation & \\
\hline WIP & $\begin{array}{l}\text { Work-in-process or } \\
\text { work-in-progress }\end{array}$ & Measured in units/day \\
\hline LCL & Lower control level & Minimum deviations of the error signal, at which \\
\hline $\mathrm{UCL}$ & Upper control level & $\begin{array}{l}\text { adaptation takes place. Measures of adaption } \\
\text { are staffing in the case of LCL, and destaffing in } \\
\text { the case of UCL (default }=0 \text { ) }\end{array}$ \\
\hline $\mathrm{P}$ & Proportional gain & Dimensionless parameters by which the error \\
\hline $\mathrm{D}$ & Differential gain & signals are multiplied to result in the adjustment \\
\hline I & Integral gain & $\begin{array}{l}\text { values (adjustments are always changes in labor } \\
\text { force, i.e., persons/day). For interpretation, see } \\
\text { the example given in the text before Table } 3 \text {. }\end{array}$ \\
\hline
\end{tabular}


Copyright of Cybernetics \& Systems is the property of Taylor \& Francis Ltd and its content may not be copied or emailed to multiple sites or posted to a listserv without the copyright holder's express written permission. However, users may print, download, or email articles for individual use. 